\title{
A CENTURY OF CHANGES IN THE MORTALITY AND INCIDENCE OF THE PRINCIPAL INFECTIONS OF CHILDHOOD
}

\author{
BY \\ A. H. GALE, D.M., D.P.H. \\ (Medical Officer, Ministry of Education)
}

This article is based on the Milroy lectures delivered before the Royal College of Physicians of London in 1944, but some of the introductory matter has been omitted and modifications and additions have been made. Its object is to give a general account of the behaviour of the chief killing diseases of children from the establishment of universal registration in July, 1837, to the present time. It is inevitably much more a study of mortality than of incidence because the information about mortality is so much more complete and goes back so much further than does that about incidence.

In his review of a hundred years of death registration the Registrar-General (Text, 1937) gave a table which showed that in the first year of civil registration, from July 1, 1837 to June 30, 1838, there were 156,817 deaths in England and Wales among children under 15 years of age. By applying the death-rates in different age groups in 1937 to the estimated population by sex and age at the end of 1837 he then calculated the number of deaths which would have occurred if the rates of 1937 had prevailed in 1837. The figure was 38,719slightly less than a quarter of the actual number of deaths registered. These figures are for deaths from all causes and include deaths from conditions peculiar to infancy and from violence which have not decreased to anything like the same extent as have those due to infections. The reduction in mortality from infections has therefore been even more remarkable than these figures suggest.

It may, at first sight, seem to be a hopeless task to give any useful picture of the history of mortality from individual infections in childhood because of their variety and because of 'the eternal difficulty of comparability between diagnosed causes of death at different epochs' (Greenwood, 1935). Though children die from many different causes the number of diseases which kill large numbers is comparatively small and most of them were well separated a hundred years ago-long before the birth of bacteriological methods of diagnosis. There are important exceptions to this last statement for deaths from scarlet fever and diphtheria were not shown separately by the Registrar-General until
1858, and those from typhus and typhoid were not separated until 1869 . This does not mean that before 1869 clinicians were incapable of distinguishing a case of typhus from a case of typhoid but only that they "were less alive to the general hygienic implications of the separation than we are' (Greenwood, 1935). There is an added difficulty about the early statistics of diphtheria in that many cases of diphtheria were thought to be due to a separate disease-' croup'-but not all cases of 'croup' were diphtheria.

In considering the trends of death-rates from separate causes there are advantages in beginning rather later than 1837 because the information available in later years is so much more complete. The next great landmarks in the history of vital statistics after the establishment of civil registration are two Supplements to the Registrar-General's Annual Reports, the first being the Supplement to the 25th Annual Report covering the ten years 1851-60 and the second the Supplement to the 35th Annual Report covering the years 1861-70. These two reports, particularly the second, may be described as the principal foundation of this paper. The Supplement to the 35th Annual Report is much more than a mere review of the ten years immediately preceding and it has been described as the 'crowning effort of Dr. Farr's labour at the General-Register Office' (Farr, 1885).

In preparing a survey of so wide a field the temptation to stray down interesting side tracks is considerable and so it seems desirable to set out certain fundamental questions to give direction to the whole study.

(1) How many children have there been in England and Wales at different times?

(2) How many have died?

(3) Of what diseases did they die?

(4) How many have suffered from those diseases for which records of incidence are available?

(5) How much information about the causes of high mortality and sickness rates in childhood can be gained from a study of their variations in time and among different sections of the population?

The first two questions are easy to answer 
reasonably accurately, but there is some inaccuracy in that, prior to the Notification Act of 1874, the notifications understated the number of births because the previous Act did not impose any penalty for failure to register. The census returns for ages 0-5 were unreliable and even in the last census of 1931 the numbers of young children differ from the totals expected from births and deaths. The third is less easy because of the great changes in medical knowledge over so long a period. The fourth is still more difficult because it depends on notification returns and the answer to the fifth question must consist in large measure of speculation.

The answer to question 1 is given in fig. 1 which

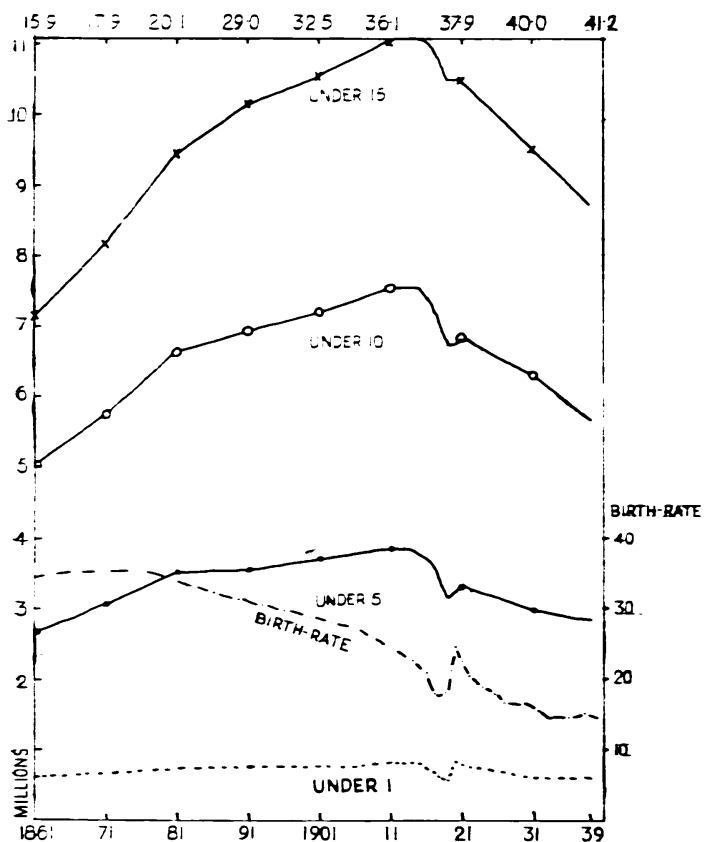

FIG. 1.-England and Wales: Populations 1861-1939. Total (millions).

shows the number of children living in different age groups at the decennial censuses since 1861. It includes also a curve of the changes in the birth-rate and details of the changes in child population in the last war based on the estimates of population given in the Registrar-General's Decennial Supplement, 1921. The total number of children under fifteen years of age rose to a maximum in the early part of the last war and has been falling ever since except for the brief rise which immediately followed the last war. The figures of total population at the top of the figure show how the proportion of children in the population has decreased.

\section{Death-rates from all causes}

Table 1 shows the annual death-rates from all causes per 1,000 living at all ages and in various age groups of childhood from the decennium 1841-50 to 1943. It is not possible to give all the recent figures because some are not available after 1940, but Stocks (1943 and 1944a) has made it possible to form an accurate picture of the trends of the rates in childhood during this war.

TABLE 1

ENGLAND AND WALES: DEATH-RATES

$$
\text { 1841-50-1943 }
$$

(Rates per 1,000 living in each age group, Infant Mortality per 1,000 Births)

\begin{tabular}{|c|c|c|c|c|c|c|}
\hline & $\begin{array}{c}\text { All } \\
\text { ages } \\
\text { (Stan- } \\
\text { dard:) }\end{array}$ & 0- & $5-$ & $10-15$ & $\begin{array}{l}\text { Infant } \\
\text { mor- } \\
\text { tality }\end{array}$ & $\begin{array}{c}1-5 \\
\text { years }\end{array}$ \\
\hline $\begin{array}{l}1841-50 \\
51-60 \\
61-70 \\
71-80 \\
81-90 \\
91-1900 \\
1901-10 \\
11-15 \\
16-20 \\
21-25 \\
26-30 \\
31-35 \\
36 \\
37 \\
38 \\
39 \\
40 \\
41 \\
42 \\
43\end{array}$ & $\begin{array}{l}21 \cdot 6 \\
21 \cdot 2 \\
21 \cdot 3 \\
20 \cdot 3 \\
18 \cdot 6 \\
18 \cdot 1 \\
15 \cdot 2 \\
13 \cdot 7 \\
13 \cdot 4 \\
10 \cdot 9 \\
10 \cdot 3 \\
9 \cdot 6 \\
9 \cdot 2 \\
9 \cdot 2 \\
8 \cdot 5 \\
8 \cdot 5 \\
9 \cdot 9 \\
9 \cdot 3 \\
8 \cdot 1 \\
8 \cdot 2\end{array}$ & $\begin{array}{l}66 \cdot 0 \\
67 \cdot 6 \\
68 \cdot 6 \\
63 \cdot 4 \\
56 \cdot 8 \\
57 \cdot 7 \\
46 \cdot 0 \\
37 \cdot 5 \\
31 \cdot 4 \\
24 \cdot 4 \\
20 \cdot 8 \\
18 \cdot 1 \\
17 \cdot 0 \\
16 \cdot 7 \\
15 \cdot 3 \\
13 \cdot 7 \\
15 \cdot 6\end{array}$ & $\begin{array}{l}9 \cdot 0 \\
8 \cdot 5 \\
8 \cdot 0 \\
6 \cdot 5 \\
5 \cdot 3 \\
4 \cdot 3 \\
3 \cdot 6 \\
3 \cdot 4 \\
3 \cdot 8 \\
2 \cdot 5 \\
2 \cdot 4 \\
2 \cdot 2 \\
2 \cdot 0 \\
1 \cdot 9 \\
1 \cdot 9 \\
1 \cdot 5 \\
2 \cdot 0 \\
2 \cdot 1 \\
1 \cdot 5 \\
1 \cdot 4\end{array}$ & $\begin{array}{l}5 \cdot 3 \\
5 \cdot 0 \\
4 \cdot 5 \\
3 \cdot 7 \\
3 \cdot 0 \\
2 \cdot 5 \\
2 \cdot 1 \\
2 \cdot 1 \\
2 \cdot 5 \\
1 \cdot 7 \\
1 \cdot 6 \\
1.4 \\
1.2 \\
1.2 \\
1.2 \\
1.0 \\
1.4 \\
1.4 \\
1.0 \\
1.0\end{array}$ & $\begin{array}{r}153 \\
154 \\
154 \\
149 \\
142 \\
153 \\
128 \\
110 \\
90 \\
76 \\
68 \\
62 \\
59 \\
58 \\
53 \\
50 \\
56 \\
59 \\
51 \\
49\end{array}$ & $\begin{array}{r}\text { (?)36.1 } \\
36 \cdot 3 \\
31 \cdot 2 \\
27 \cdot 0 \\
24 \cdot 3 \\
18 \cdot 4 \\
16 \cdot 2 \\
14 \cdot 6 \\
10 \cdot 3 \\
8 \cdot 6 \\
6 \cdot 6 \\
5 \cdot 5 \\
5 \cdot 1 \\
4 \cdot 6 \\
3 \cdot 5 \\
4 \cdot 8 \\
5 \cdot 3 \\
3 \cdot 4 \\
3 \cdot 3\end{array}$ \\
\hline
\end{tabular}

Figure 2 is intended to facilitate comparison of the rates of change of death-rates in the different age groups. It has been plotted on logarithmic graph paper instead of on ordinary arithmetic graph paper because this method of plotting gives a better picture of the general trend of rates and because it is easy, by this method, to compare the trend of rates which have widely different absolute values.

As the method may be unfamiliar a simple example may be desirable. Suppose it is desired to show graphically the behaviour of two diseases $\mathbf{A}$ and $\mathbf{B}$. $A$ has rates in successive periods of 200,100 and 50 per million living. B is a less common cause of death and in the same successive periods has rates of 40,20 and 10 per million living. Figure 3a shows the result of plotting these rates on ordinary graph paper and figure $3 \mathrm{~b}$ the result of plotting on logarithmic graph paper. The arithmetic graph (3a) gives the impression that $\mathbf{A}$ is declining faster than $\mathbf{B}$ whereas the rate of decline is really the same, one-half for both experiences. On the logarithmic graph (3b) the rate of decline is clearly seen to be the same.

In figure 2 the continuous lines represent the rates in the age groups $0-5,5-10,10-15$ years, and the dotted lines represent a further analysis of the rate $0-5$, i.e. the infant mortality rate per 100 births and the rate in the age group 1-5. It is clear that the rate 0-5 follows much the same trend as that of infant mortality, but the rate $1-5$ follows a rather 


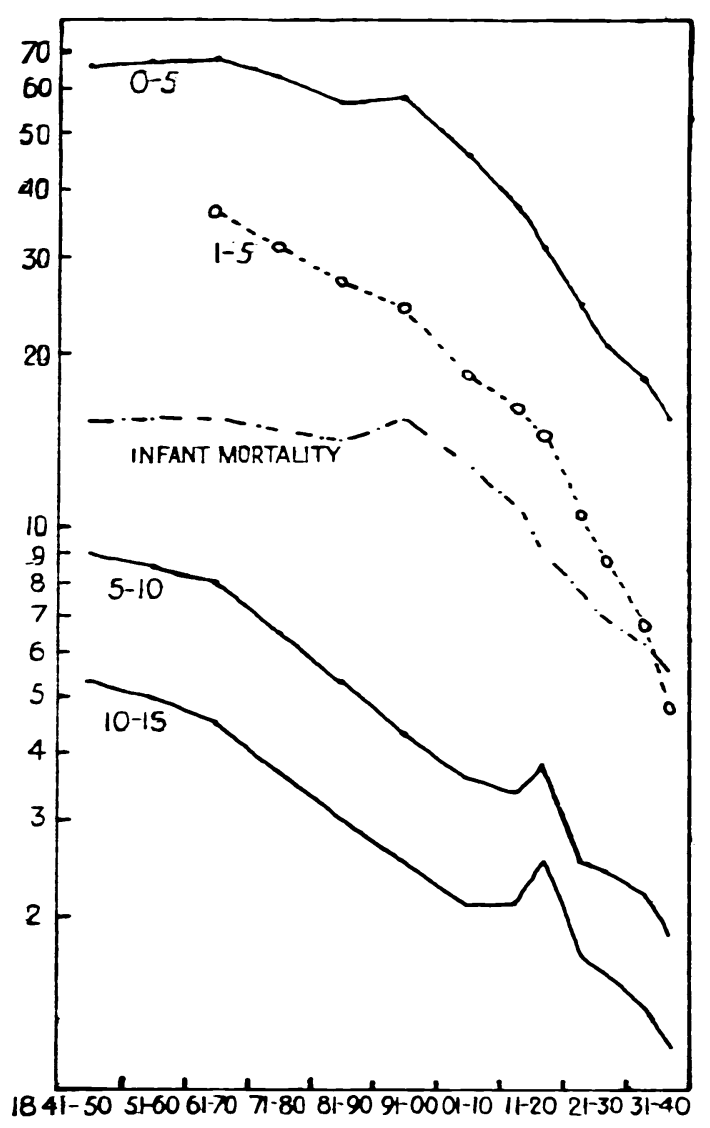

FIG. 2.-England and Wales: Death rates (per 1,000 living) in different age groups of childhood. Infant mortality (per 100 births). 1841-50 to 1931-40. Logarithmic scale.
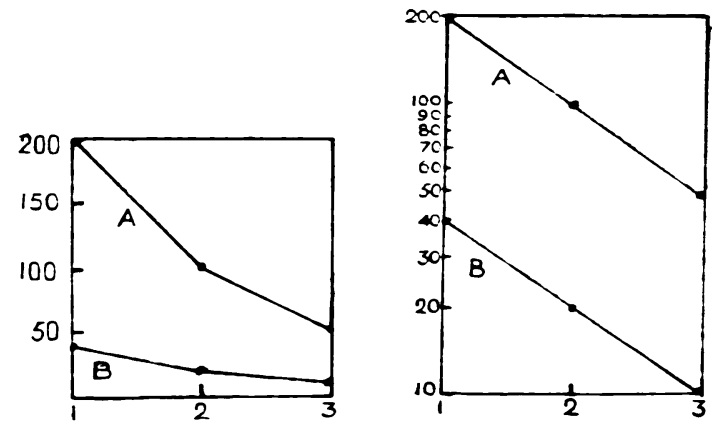

FIG. 3.-Graphs to show difference between plotting on ordinary (arithmetic) and logarithmic graph paper.

different course. Infant mortality did not begin to fall until about 1900 , but since then the fall has been continuous and fairly steady. The rate in the age group 1-5 was almost stationary between 1840 and 1870 and began to fall in the decennium 1871-80. It fell slowly at first but more rapidly from about 1900 and rapidly from soon after the last war to the present time. The rates for older children show a slow fall for about the first thirty years then a more rapid fall arrested in the quinquennium 1911-15 and rising in the quinquennium 1916-20. This rise was chiefly due to the pandemic of influenza of 1918 and is more marked in the $10-15$ curve than in the 5-10 curve. After the last war the fall continued and was accelerated from about 1935. Figure 4 shows the course of events in different age groups from 1911 to the present time in greater detail. It will be seen that while the rates at $0-1$ (infant mortality), 1-5, 5-10 and 10-15 have all been falling more or less continuously from 1918, they have not all fallen at the same speed or in the

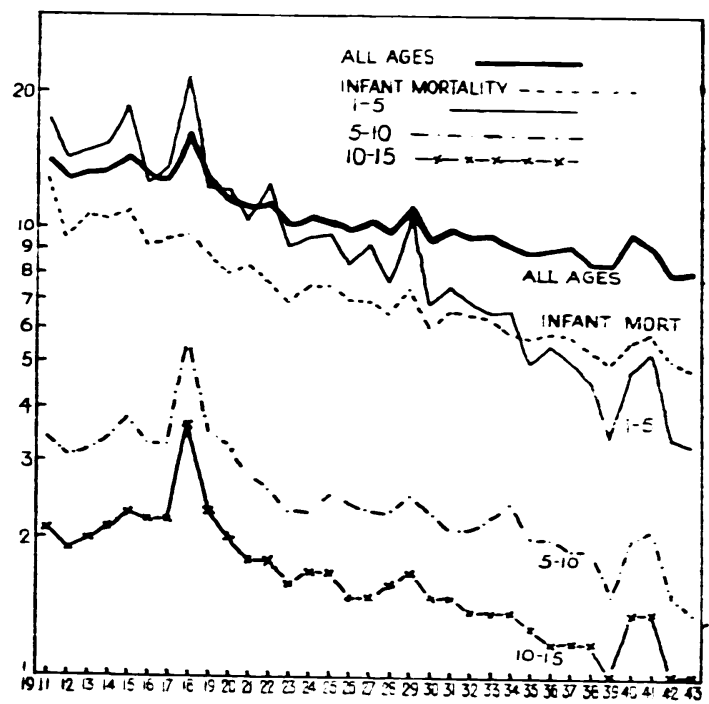

FIG. 4.-England and Wales: Death-rates from all causes at all ages (stand.): Age group 10-15; 5-10; 1-5: infant mortality (per 100 births). Rates per 1,000 living. Individual years 1911-43. Logarithmic scale.

same way. The peaks in 1918 were chiefly due to the pandemic of influenza and it is interesting to note that the rates for older children were affected most and the infant mortality rate hardly at all. The high infant mortality in 1911 was due to diarrhoea coincident with a hot summer, but after 1911 epidemics of diarrhoea decreased in severity and the last one noticeable on the curve of infant mortality from all causes is that of 1921 (see also fig. 18). The peaks on the 1-5 curve were due to high rates from broncho-pneumonia, measles and whooping-cough occurring alone or in combination. The fluctuations of the 5-10 and 10-15 curves were associated chiefly with variations in the mortality of diphtheria. The low levels for 1939 and 1942 are obvious. It is not easy to be sure of any marked correspondence of trend in the different curves, except for the general downward one, but there is a suggestion of a rapid fall after the last war followed by a period of arrest or slower fall and then another rapid fall from about 1934 .

\section{Course of death-rates from principal causes}

So far the rates from all causes have been considered. Table 2 compares infant mortality per 
1,000 births from principal causes in 1873-75 with infant mortality in 1931-35 and death rates from the principal causes in different age groups of childhood (1-5, 5-10 and 10-15) in 1861-70 with those in 1931-35. It is impossible to discuss all the changes in medical knowledge and in methods of classification which may have affected comparability between the earlier and the later figures, and it is not intended that the table should be regarded as more than a rough comparison of the relative importance of different causes at two widely separated epochs. There are, however, certain features so obvious that they must be due to real changes. In the figures of infant mortality an attempt has been made to separate the deaths due to conditions peculiar to early infancy, roughly corresponding to neonatal mortality, from those due to infections. It is, however, well known how difficult it is, even now, to separate infant deaths into these two main groups and it is much more difficult to do this for deaths which occurred many years ago. If it is assumed that the deaths after the first month from prematurity and allied causes roughly cancel out the deaths during the first month from infections, the neonatal rate in 1873-75 was 40.9. Applying the same line of reasoning to the figures for 1931-35 the neonatal rate works out at 29.03 , whereas the actual figure for the later period, calculated from the number of deaths which really occurred under four weeks, was 31.4 . The true neonatal rate is not available for the earlier period.

The great importance of the indefinite group of lung diseases, chiefly bronchitis and pneumonia, and particularly among younger children, is obvious both in the earlier and in the later figures. Another indefinite group which caused a high mortality among young children in the earlier period is that of 'brain diseases.' These deaths appeared largely under the sub-heading of 'convulsions.' It is impossible to say what were the true causes of these deaths, but probably the minority were due to true disease of the central nervous system and the

TABLE 2

Infant mortality per 1,000 births

England and Wales: Death-rates per million living 1861-70

England 1873-75

Lung diseases
Convulsions $\ldots$
Diarrhoea $\ldots$
Tuberculosis . .
Whooping-cough
Teething $\quad$..
Measles
Scarlet fever

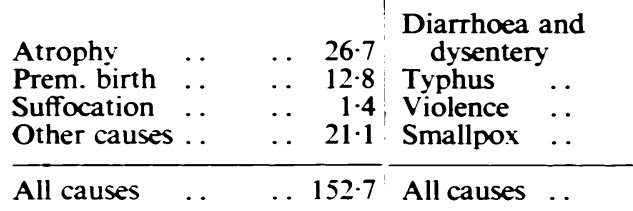

$1-5$

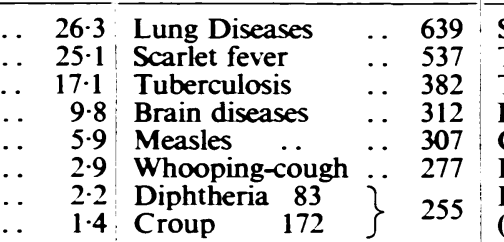

193

. 137

.
.

47
$5-10$

$10-15$

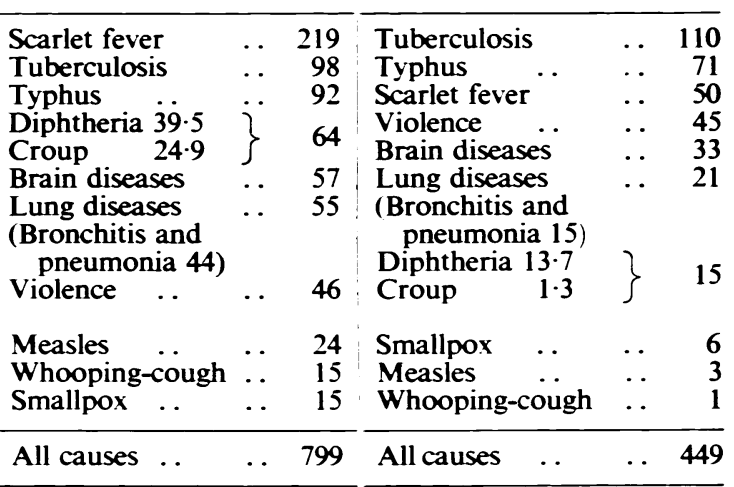

$1931-35$

England and Wales: 1931-35

$1-5$

5-10

$10-15$

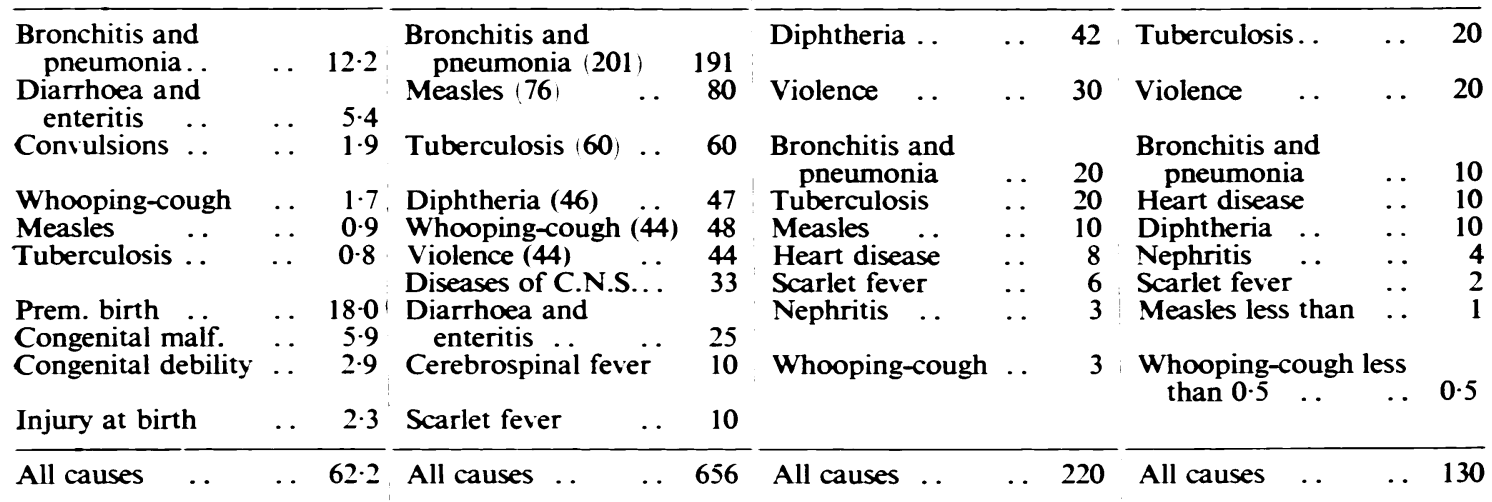

Figs. in brackets are according to 1940 method of classification. 
majority were due to other infections. As a recorded cause of death 'convulsions' has been decreasing steadily as certification has improved. Scarlet fever which used to be such a terrible scourge among children, particularly among those of school age, is no longer an important cause of death. The death-rates from other common infectious diseases have decreased considerably and so have those from tuberculosis and the intestinal infections.

The next two figures (5 and 6) show the trends, on a logarithmic scale, of death-rates of certain diseases or groups of diseases. For the common infectious diseases (fig. 5) the rates for the whole age period 0-15 have been chosen because these rates are easily available. For bronchitis and pneumonia, diarrhoea, tuberculosis and smallpox

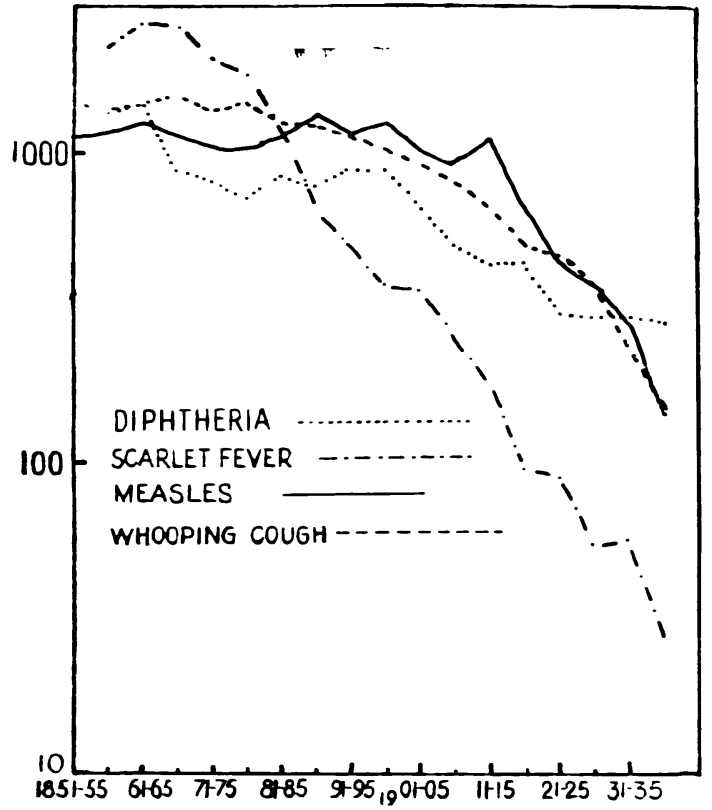

Fig. 5.-England and Wales : Age group 0-15. Deathrates (quinquennial periods) per million living from common infectious diseases. Logarithmic scale.

(fig. 6) the rates in the age group 0-5 have been used. Fig. 5 brings out the point, which is not clear on an ordinary arithmetic graph, that the death-rate from scarlet fever has been decreasing rapidly and continuously since about 1875 except for three short periods of arrest. The death-rates of most of the infections of childhood began to decline about the beginning of the century, but smallpox and scarlet fever began to decline earlier and measles rather later. Rates for all diseases except diphtheria have continued to fall, but the recent history of that disease will be considered later.

Figures 7 and 8 show the trends of death-rates from important infections in the age group 1-5 from 1911 to 1942 . Fig. 7 is constructed from averages of the rates over four-year periods because the diseases shown vary so much from year to year that a graph showing rates for each year separately would be very confusing. The diseases shown in fig. 8 do not vary so much in incidence from year

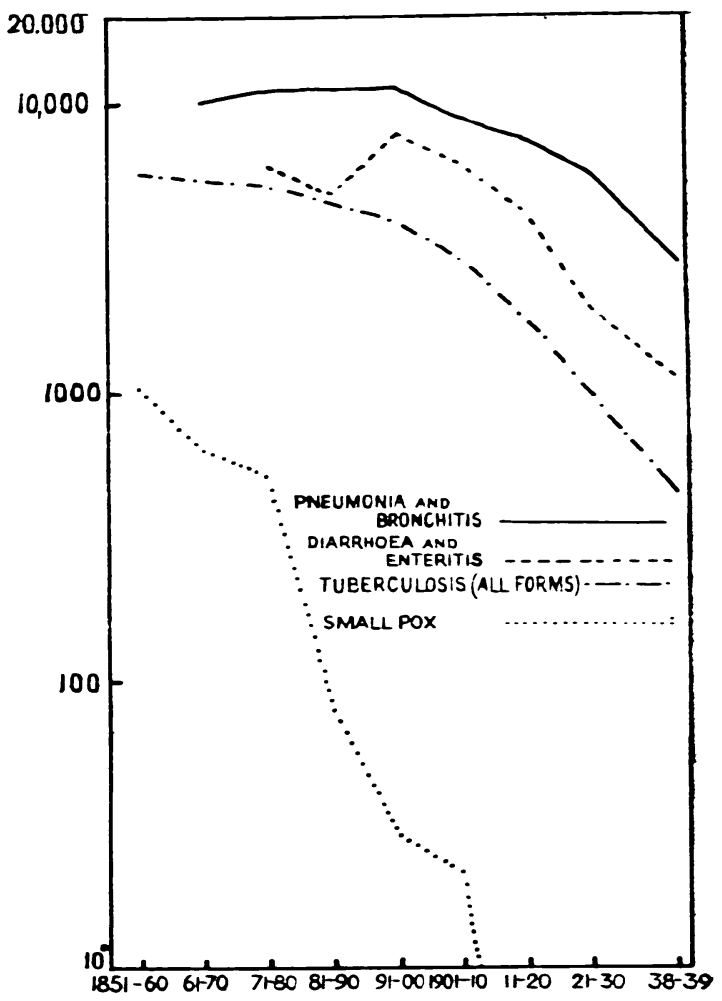

FIG. 6.-England and Wales : Age group 0-5. Death rates per million living from bronchitis and pneumonia; diarrhoea and enteritis; tuberculosis (all forms); smallpox. Decennial periods except for last point-1938-39. Logarithmic scale, 1851-1939.

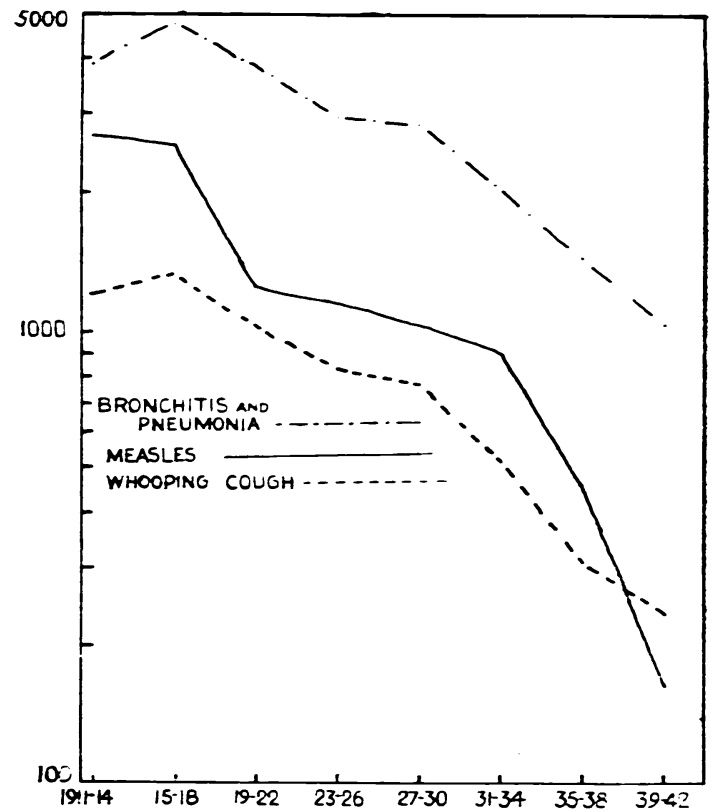

FIG. 7.-England and Wales: Age group 1-5. Deathrates per million living from bronchitis and pneumonia: measles; whooping-cough. Averages of annual rates over four-year periods. Logarithmic scale, 1911-1942. 


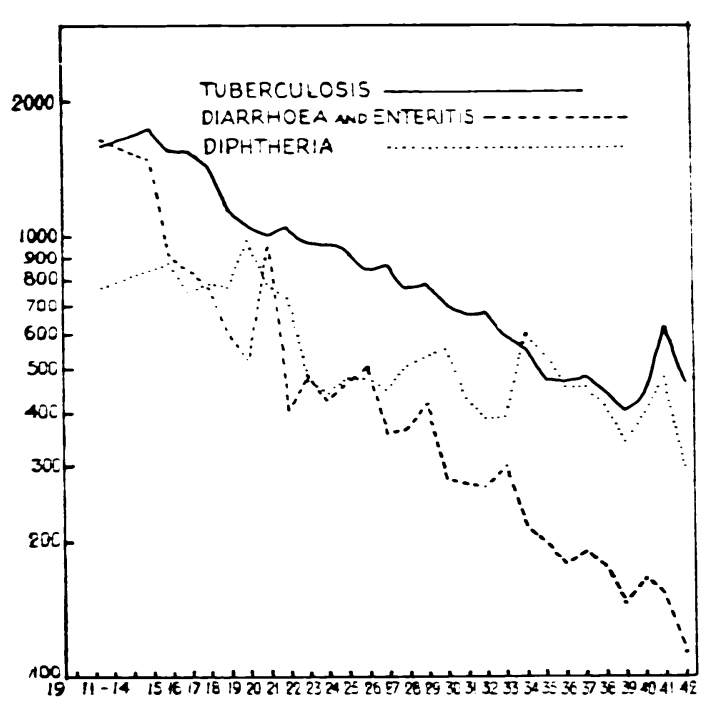

FIG. 8.-England and Wales: Age group 1-5. Deathrates per million living from tuberculosis (all forms): diphtheria and enteritis. First point is rate for 1911-14 and subsequent rates are annual 1911-14 to 1942. Logarithmic scale.

to year and so annual rates are shown. Both graphs are on logarithmic paper. The rates for the years of the last war are taken from the Registrar-General's annual reports for those years, those from 1921 to 1935 from the Registrar-General's Annual Review (Text) 1937, and those for recent years from Stocks (1943). The three series are not strictly comparable but the inaccuracies are so small that they do not affect the general picture, and it seemed better to use rates as they appeared in the Registrar-General's reports than to attempt complicated adjustments. It is difficult to be sure of any common trend in curves which differ considerably, but there is perhaps a common tendency to fall after the last war, then a period of arrest, particularly well marked in the measles curve, and a further fall.

\section{The history of individual diseases}

As an introduction to the study of individual diseases it may be of interest to describe the general picture of epidemic disease in this country as it appeared to Simon (1890) during his period of office as Medical Officer of the Privy Council, 1858-72.

When he first entered on his duties (1858) ' diphtheria had recently begun to be a source of much alarm to the public and of great interest to the medical profession as a disease which (though it had been experienced in former times) was wellnigh unknown to the existing generation of British medical practitioners.' He also mentions outbreaks of typhus (1862-63) associated with distress in the cotton towns, and a ' strange ' disease spreading epidemically in Northern Europe. - This was cerebrospinal meningitis-a febrile nervous affection of an extremely painful and dangerous kind, which we in England had hitherto hardly heard named and which on the continent had been but recently identified." In 1865 the fourth pandemic of Asiatic cholera invaded Europe and spread to England. In addition to these special subjects of inquiry the medical department under the Privy Council carried out investigations of the high fatality of diarrhoea (1859) and of infant mortality (1861) in certain industrial towns and in East Midland (1863) agricultural districts. These were special inquiries and throughout the period various epidemics of the more common diseases-generally enteric fever, typhus or scarlatina - were investigated.

A mere glance at table 2 will show that more children have died from bronchitis and pneumonia since 1861 than from any other of the causes shown and it would be logical to begin the study of disease groups with them, but the group is ill-defined and little is known about incidence. It therefore seems better to begin with the common infectious diseases -measles, scarlet fever, diphtheria and whooping cough, and to consider first mortality rather than incidence because there is less statistical information about incidence than about mortality and it begins much more recently. Figures of mortality which are easily available date from the quinquennium 1851-55 whereas those of incidence, for England and Wales as a whole, start in 1911 for diphtheria and scarlet fever and only in November 1939, for measles and whooping-cough.

Mortality. Fig. 5 shows, on a logarithmic scale, the death-rates per million children living under fifteen years of age from 1851 to 1940 . Those for diphtheria include those of 'croup,' as there was considerable confusion about the classification of deaths from diphtheria up to the end of the nineteenth century. In his Decennial Supplement 1921, the Registrar-General says:-

- In the first twenty years of civil registration there is no doubt that diphtheria did not prevail extensively as an epidemic disease in England and Wales. Prior to 1855 it is probable that most of the deaths ascribed to croup were not due to diphtheria and from 1910 on the deaths ascribed to it were not mainly due to diphtheria but between those two dates many were.

The reduction of the death-rate from scarlet fever is the most remarkable feature of fig. 5, but the curve of measles is only a little less remarkable for the rate was almost exactly the same in the quinquennium 1911-15 as it had been in the quinquennium 1851-55, but by the quinquennium 1936-40 it had fallen to about one-eighth of its value in 1911-15. The death-rate of whoopingcough declined fairly steadily after 1880 , but the decline was greatly accelerated after the last war. As both measles and whooping-cough are rarely fatal after the age of five and vary greatly in prevalence from year to year, their recent history can best be traced in figs. 7 and 11 . The earlier part of the curve for diphtheria and croup (fig. 5) is suspect because of the statistical difficulty already mentioned, but from about 1900 there was a steady fall, a plateau in the years of the last war, a sharp fall from 1921-25 and then another plateau lasting up 
to the very recent fall (1942-43) which is shown in fig. 9. The recent history of the four common

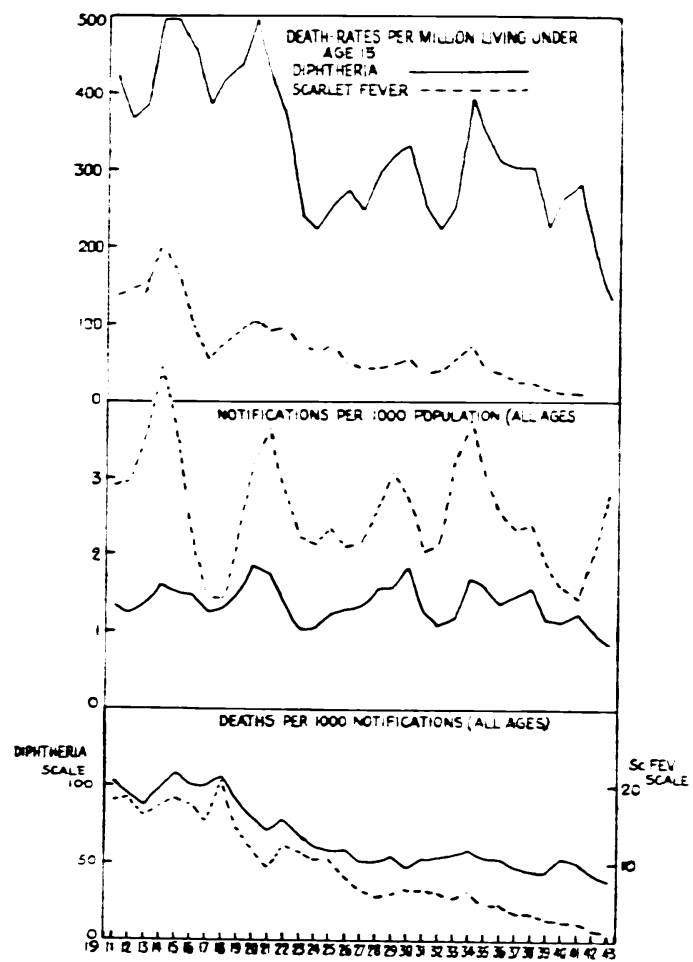

FIG. 9.-England and Wales: Diphtheria and scarlet fever. Mortality; incidence; case fatality, 1911-43.

infectious diseases is shown in table 3 taken from Stocks (1943).

Rates for 1943 are not available as yet in the same form as those given in the table but the figures of deaths at all ages published in the RegistrarGeneral's Quarterly Returns indicate that the rates for 1943 are likely to be somewhat as follows:-

Measles-higher than in 1942, which was a nonepidemic year, but lower than in 1941 .

Whooping-cough-higher than in 1942 but not so high as in 1939.

Scarlet fever-about the same as in 1941.

Diphtheria - this rate is likely to show the most striking reduction and to be substantially below the low records of 1942 .

The distribution of deaths. There is one important feature of death-rates from infectious disease which has been described by the Registrar-General
(Text 1937) and is discussed by Russell (1943) particularly in diphtheria but may apply to the other diseases also. This is the age-shift of mortality from the younger to the older ages. In 1906-10 and 1931-35 the comparative death-rates from diphtheria at ages may be expressed thus :-

\section{TABLE 4}

DIPHTHERIA: DEATH-RATES IN AGE GROUPS 0-5 AND 10-15 EXPRESSED AS PERCENTAGE OF THE RATE IN AGE GROUP 5-10

$\begin{array}{ccccc} & & & 1906-10 & 1931-35 \\ 0-5 & \ldots & \ldots & 163 & 95 \\ 5-10 & \ldots & \ldots & 100 & 100 \\ 10-15 & . & . & 15 & 24\end{array}$

There is some evidence in the recent figures (Stocks, 1944a and Ministry of Health, 1944) that extensive immunization of children between the ages of one and fourteen is lowering the death-rates at those ages, whereas the rates for children under one and for persons over 15 are unaffected.

Cheeseman, Martin and Russell (1939) have expressed the view that this movement of mortality of diphtheria to older ages may have been due to a considerable extent to the reduction of family density resulting in a later age of infection. Russell (1943) develops the idea in his recent survey of the epidemiology of diphtheria in the last forty years. If this explanation of the change in diphtheria mortality is true it seems likely that a similar process may have affected the death-rates of measles and whooping-cough. Both these diseases are, practically speaking, fatal only to children under school age and so any postponement of the age of infection would lead to general reduction of mortality. The measles rate fell suddenly from about 1915 and there was some acceleration of the rate of fall of the death-rate of whooping-cough about the time of the last war though this is not so clearly marked as with measles because the rate of whooping-cough had been falling steadily for many years. Hilda Woods (1933) described a similar age shift in the mortality of scarlet fever between 1901 and 1921 .

When considering diseases which vary so much in incidence as do the common infectious diseases of childhood it is clearly necessary to study deathrates and incidence together before drawing any conclusions about fatality. This is particularly true of measles and whooping-cough because they have large short-term fluctuations of incidence, but unfortunately it is not possible to study incidence of these two diseases before November, 1939. It is

TABLE 3

DEATH-RATES PER MILLION LIVING (1-5) FROM COMMON INFECTIOUS DISEASES $1931-35$ TO 1942

\begin{tabular}{|c|c|c|c|c|c|c|c|c|c|}
\hline Cause & & $1931-35$ & 1936 & 1937 & 1938 & 1939 & 1940 & 1941 & 1942 \\
\hline $\begin{array}{l}\text { Measles .. } \\
\text { Whooping-cough } \\
\text { Diphtheria .. } \\
\text { Scarlet fever }\end{array}$ & $\begin{array}{l}\cdots \\
\cdots \\
\cdots\end{array}$ & $\begin{array}{l}758 \\
444 \\
457 \\
100\end{array}$ & $\begin{array}{r}759 \\
382 \\
455 \\
73\end{array}$ & $\begin{array}{r}276 \\
330 \\
454 \\
57\end{array}$ & $\begin{array}{r}419 \\
221 \\
414 \\
57\end{array}$ & $\begin{array}{r}71 \\
221 \\
342 \\
30\end{array}$ & $\begin{array}{r}208 \\
128 \\
398 \\
19\end{array}$ & $\begin{array}{r}273 \\
475 \\
482 \\
25\end{array}$ & $\begin{array}{r}111 \\
133 \\
303 \\
12\end{array}$ \\
\hline
\end{tabular}


less true of scarlet fever and diphtheria, but even they show substantial fluctuations which tend to follow the same course and to show an irregular periodicity. Fig. 9 shows how incidence, mortality and fatality of diphtheria and scarlet fever have been related since 1911. As figures for notifications divided into age groups are only just available for the whole country, the graphs of incidence and case fatality relate to the whole population. In a way the top graph may be described as the resultant of the two lower ones for obviously the death-rate of a disease depends on two factors-how common it is and how fatal. The fatality of both these diseases declined by about half between 1919 and 1927, but the death-rate did not follow quite the same trend because prevalence of both diseases was rising substantially in 1919 and 1920 and reached a peak for diphtheria in 1920 and for scarlet fever in 1921.

There is one particularly puzzling feature of the figures of notifications of these two diseases and that is their constancy over a period when the relative proportion and even the actual number of children in the population was falling considerably. Figures of notification are notoriously unreliable and there has been an increasing tendency to notify doubtful cases of diphtheria (there is inadequate provision under existing administrative arrangements for correcting wrong initial diagnosis but steps are being taken to alter this), but it seems doubtful if scarlet fever is notified more freely now than formerly. Figures of notifications for some of the larger cities go back further than the national statistics and for a number of years the Medical Officer of Health of Liverpool (1938) has given graphs showing the incidence of diphtheria and scarlet fever in the city since 1890 . These graphs show fluctuations similar to those in fig. 9 but, on the whole, the notification rate for diphtheria has been on the increase and that of scarlet fever has remained the same. The evidence as to the incidence of measles is even less satisfactory because the disease has been generally notifiable for so short a time, but the number of cases reported from the schools has not changed materially from epidemic to epidemic (Brincker, 1938; London, 1927-36). Such evidence as there is, therefore, suggests that diphtheria, scarlet fever and measles are no less prevalent now than they were at the beginning of the century.

In 1942 there was a definite and most unusual movement downward of the diphtheria notifications at a time when the scarlet fever notifications were rising. This is clearer on the short-term graph (fig. 10).

Russell (1943) has critically examined the evidence that large-scale immunization against diphtheria in the United States and in Canada has affected the morbidity and mortality rates. He concludes that ' there is very strong evidence that immunization, particularly since the inclusion of the pre-schoo children, has reduced the morbidity and mortality from diphtheria in New York City and in Toronto.' Until recently immunization had not been practised in this country to an extent which would justify the search for signs of it in the national statistics, but by December 31,1942 , it was estimated that rather more than half the children under 15 in England and Wales had been immunized (Ministry of Health, 1944).

The recent history (1938-43) of the four common infectious diseases is given in fig. 10 which shows weekly notifications and deaths at all ages. The approximate position of school holidays and of the period of school closure in evacuation areas in 1939-40 has been indicated. The effect of school closure and of school holidays is obvious. Stocks (1941, 1942) has examined in detail the effect of dispersal on the incidence of all four diseases. He found that the incidence of diphtheria and scarlet fever was substantially reduced in the evacuation

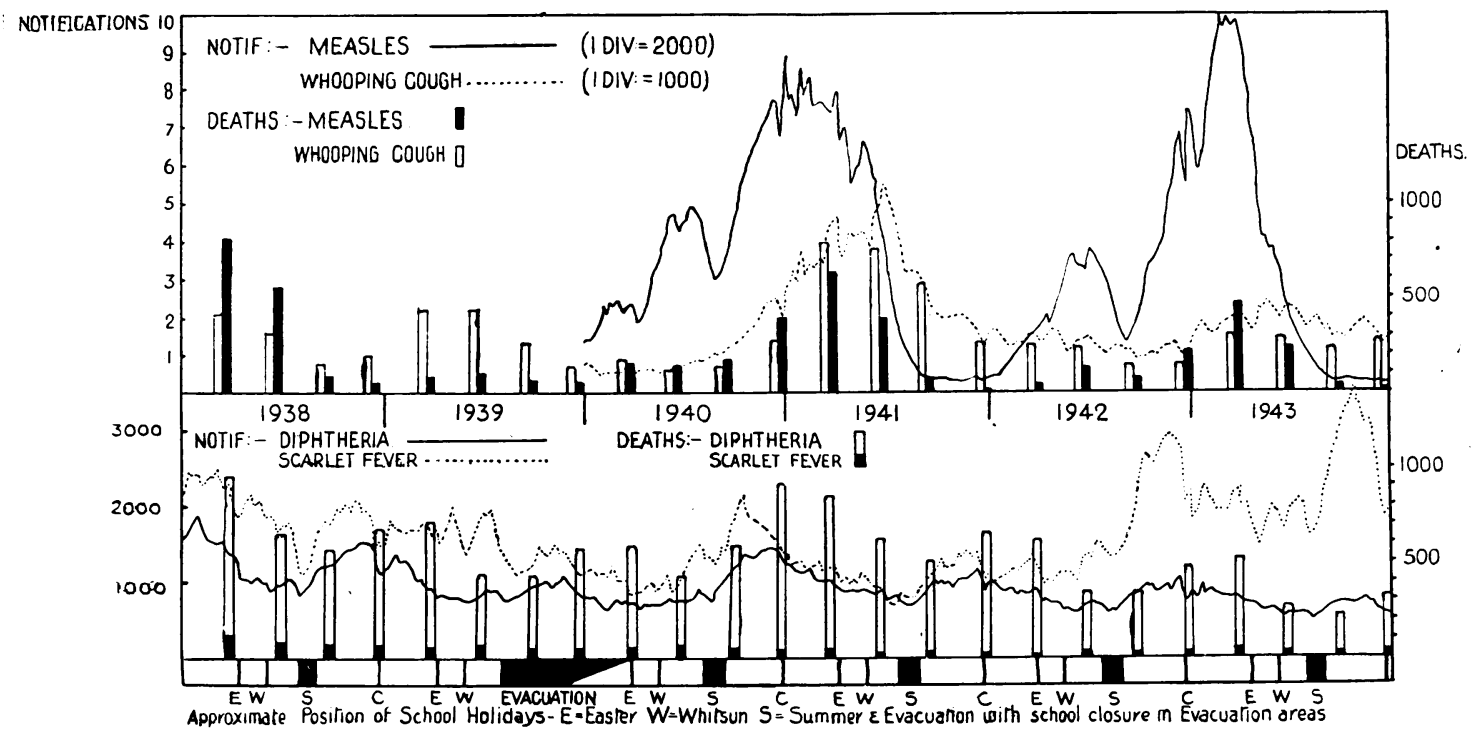

FIG. 10.-England and Wales: Weekly notifications of infectious diseases and quarterly deaths (both all ages). 1938-1943. 
areas and was increased in the reception areas. It was less easy to determine the effect of dispersal on the incidence of measles and of whooping-cough because of the absence of figures of notifications for previous years, but the evidence suggested strongly that dispersal disturbed the usual periodicity of measles and reduced the incidence of whoopingcough in the evacuation areas. The evacuation areas contained so large a proportion of the child population that the national figures shown in fig. 10 show chiefly what was happening in those areas.

Pneumococcal and streptococcal infections. It is well known that nearly all deaths ascribed to measles or to whooping-cough are due to complications rather than to the disease itself and that most of the complications are either pneumococcal or streptococcal infections. Fig. 11 shows the annual

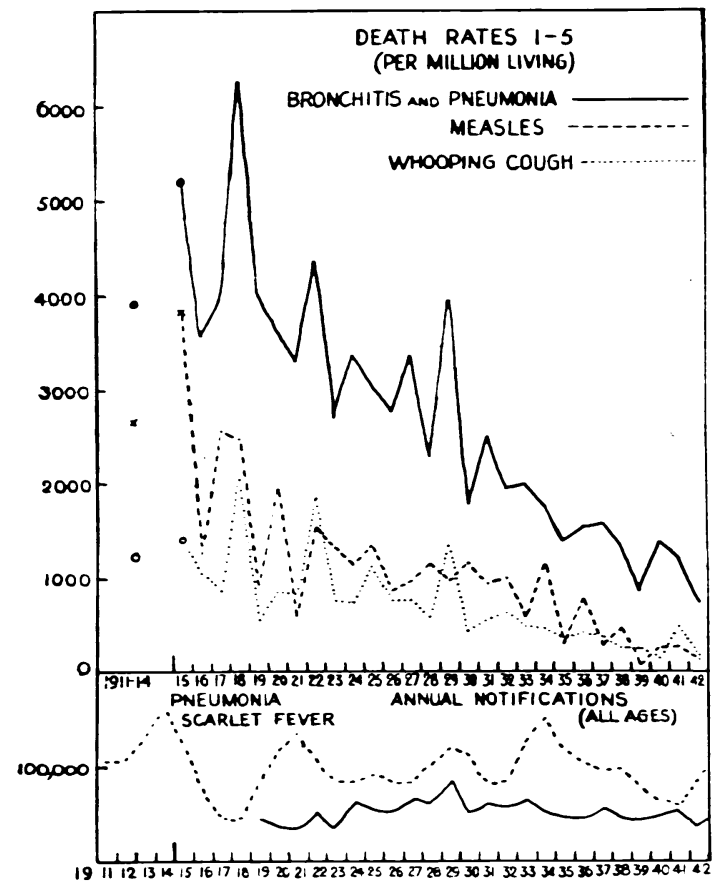

FIG. 11.-England and Wales: Death-rates per million living in age group 1-5. 1911-14 to 1942 from bronchitis and pneumonia; measles; whoopingcough. Notifications of pneumonia and scarlet fever.

death-rates from measles, whooping-cough and bronchitis and pneumonia in the age group 1-5 and the annual notifications of scarlet fever at all ages. It is intended to show the relationship of the shortterm fluctuations of the different diseases. Whooping-cough and bronchitis and pneumonia have the same peaks of mortality-in 1918, 1922 and 1929though whether this is due to a true association of the two or to difficulties of differential diagnosis is uncertain. Measles has such irregular oscillations and the rate is so different in epidemic and in nonepidemic years that it is difficult to make any generalization about it, but there is perhaps a tendency for the rate to be high when notifications of scarlet fever are also high. For description of the trend of death-rates it is convenient to separate pneumococcal and streptococcal infections, but the distinction is not clear-cut because clinical classifications, on which death certificates are based, do not correspond with etiological classifications.

PNeumococCal Infections. In the year 1939, which was a year of remarkably low mortality from infections in childhood, 17 per cent. of all deaths occurring in children under 15 years were ascribed either to bronchitis or to pneumonia, and in 1940 the corresponding figure was 21 per cent. Throughout the period under review bronchitis and pneumonia have been the most important causes of death in children under five and have been among the most important causes in older children (see table 2). The way in which the rates in different age groups have fallen since $1861-70$ is shown in fig: 12. The rates for the age groups 5-10 and 10-15

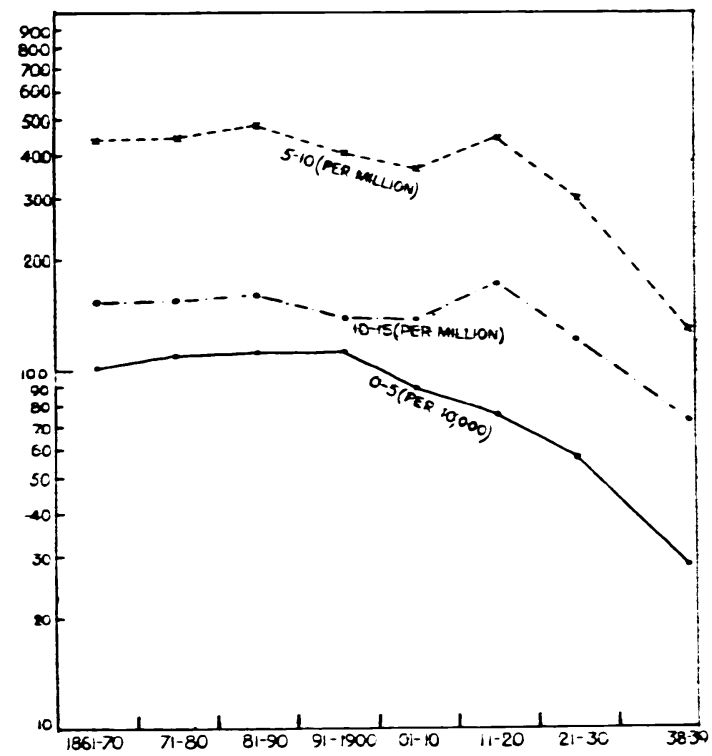

FIG. 12.-England and Wales: 1861-70-1938-39. Death-rates from bronchitis and pneumonia in different age-groups. Logarithmic scale, rates 10-15 and 5-10 per million: 0-5 per 10,000 .

began to fall rather earlier than that for the age group 0-5 but rose in the decennium 1911-20. This rise was probably due to the pandemic of influenza in 1918 which affected the death-rates of older children more than those of younger ones. Fig. 13 describes the recent behaviour of pneumonia and influenza and notifications of scarlet fever have been included to serve as a link with fig. 14 which is concerned with certain streptococcal diseases. Fig. 13 shows how closely interrelated are the rates for influenza and for bronchitis and pneumonia though it is impossible to say how far this is due to difficulties of diagnosis and how far it is due to a true association of different diseases. It should be noted that only acute primary and influenzal pneumonia are notifiable diseases, so that notifications do not give a complete picture of the incidence of all forms of pneumonia. 


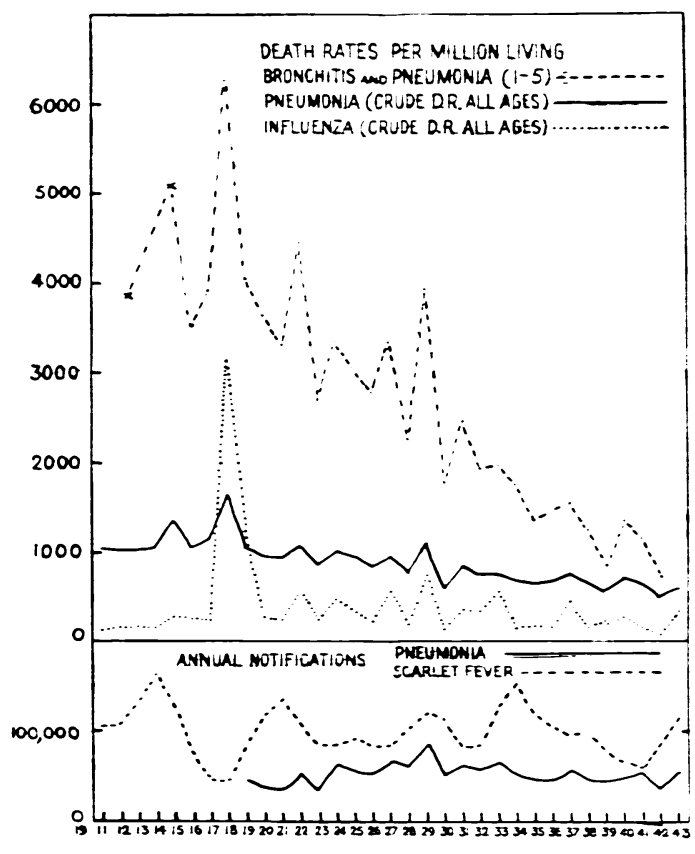

FIG. 13.-England and Wales: Crude D.R.s per million from pneumonia (all forms) and influenza: D.R. from bronchitis and pneumonia (age-groups 1-5, per million living), 1911-43. Annual notifications of pneumonia and scarlet fever.

Streptococcal INFECTIONS. It is, unfortunately, impossible to give even an estimate of the total number of deaths among children due to streptococcal infections. Allison (1942) says ' the haemolytic streptococcus is probably the most dangerous of the common infecting agents and is certainly the most protean in the diseases it produces.' These generalizations are particularly true in their application to children, but, because of the difficulty of selecting diseases which are predominantly streptococcal in origin and also affect children rather than adults, fig. 14 shows crude death-rates at all ages from certain predominantly

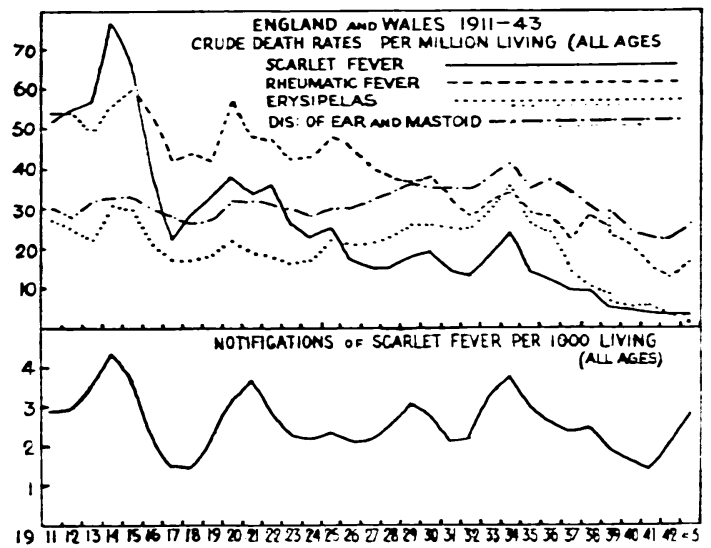

FIG. 14.-England and Wales: Crude death-rates (all ages) of certain predominantly streptococcal diseases, and notification rates of scarlet fever: 1911-43. streptococcal diseases together with notification rates of scarlet fever. Although the association is not perfect there is sufficient evidence to suggest that death-rates from streptococcal diseases generally tend to move up and down together and to be associated with changes in the prevalence of scarlet fever. The wave of streptococcal activity which had its peak in 1934 is an obvious example of association. Puerperal sepsis has been omitted from the figure partly to avoid confusion and partly because changes in methods of classification make it difficult to construct a satisfactory long-term curve. There is no doubt, however, that the death-rate from puerperal sepsis has followed a similar course to the diseases shown. It is justifiable, therefore, to regard notifications of scarlet fever as a sort of biological indicator of streptococcal activity generally and so these notifications have a value which is not affected by any argument as to their value in the control of the disease itself.

Rheumatism. Juvenile rheumatism has been the object of many detailed studies and here it is appropriate only to summarize the main facts and to try to put them in relation with the facts about other infections which have already been given.

The death-rate from rheumatic fever per million living in the age group 10-15 fell from about 100 in the decennium 1891-1900 to about 47 in 1937, and there has been a further decline since then though it is not possible from the published figures to state it in exactly the same terms. The death-rate from rheumatic fever does not, however, give a complete picture of the mortality of the disease because deaths due to valvular disease of the heart are ascribed to rheumatism only when it is stated on the certificate that active disease was present at the time of death. A modification of Glover's (1943) graph (fig. 15) of the numbers of deaths under 15 years of age from rheumatic fever, from heart disease and from scarlet fever from 1928 to 1941 gives a better picture of the recent fall for, as he says, it may be assumed that at least nine-tenths of the deaths ascribed to heart disease in this age group are due to rheumatism. Of the exact numbers of children who have damaged hearts as a result of rheumatism there is no exact information, but it is known that something like half the children in schools for physically defective children are cardiac cripples. These are only the more serious cases and there must be many children leading more or less normal lives and attending ordinary schools who have suffered some damage. The proportion of children in schools for physically defective children who are admitted because they have heart disease has been increasing for many years: not because the absolute number of them has been increasing but because greater care has been taken to detect cases and to give them suitable education. Glover (1930) described rheumatic fever as an obsolescent disease and subsequent events have tended to confirm that view. It is of interest to note that although the sulphonamides are of doubtful value in the treatment of rheumatism the decline 


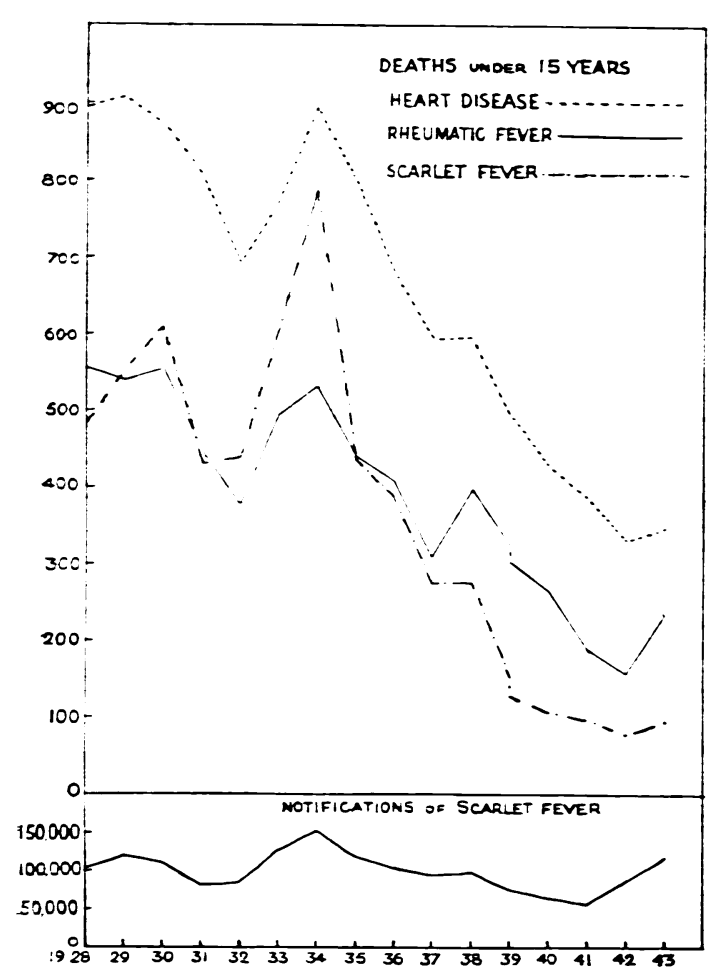

Fig. 15.-England and Wales: Deaths from heart diseases, rheumatic fever, scarlet fever at ages under 15 years. Notification of scarlet fever (all ages): $1928-43$.

has been particularly rapid recently and has been comparable with that of the diseases for which sulphonamides are effective. Some of this decline is due to the fact that streptococcal activity generally was at a low level in 1939-40, and the slight increase in activity which has occurred recently has caused a slight increase in deaths from rheumatism (fig. 15). This is probably only a comparatively small and temporary effect and not important in comparison with the long-term reduction of mortality.

Tuberculosis. In that part of table 2 which relates to the 'sixties and 'seventies, tuberculosis (all forms) is fourth in the list of infections in the column of infant mortality, third in the age group 1-5, second in the age group 5-10 and first in the age group 10-15. In 1931-35 the relative position of tuberculosis in the various age groups is not very different, but the rate is reduced to about onetwelfth of that in 1861-70 in the case of infants, and between one-seventh and one-fifth in the older age groups. The general trend of rates in the different age groups is shown on a logarithmic scale in fig. 16. All the rates have been falling since $1851-60$, but that of the age group 0-5 fell slowly until 1891-1900, and then more rapidly. The rate in the age group 5-10 fell steadily until the last war, remained stationary in the war, and then fell rapidly. That of the age group 10-15 had much the same trend, except for a definite rise in the quinquennium 1916-20. In young children tuberculosis is like most other infections in that the death-rate of males is higher than that of females, but in the age group $5-10$, the rates are much the same for both sexes, and in the age group 10-15, that of females is substantially higher than that of males. Among children under five, the deaths are chiefly due to tuberculous meningitis, whereas with increasing age. respiratory tuberculosis becomes more important as a cause of death. The behaviour of tuberculosis in this war, up to the end of 1941, and in the last one has been compared in a report by a committee of the Medical Research Council (1942). Table 5 is taken from that report, with the figures for 1931-35, 1942 and 1943 added. The average figures for 1931-35 are included to link the table with fig. 16. The principal difference between this war and the last one has been that in the last one the deaths from respiratory tuberculosis increased, while the deaths from tuberculous meningitis decreased, whereas in this war both increased to some extent.

The earlier history of tuberculous meningitis is difficult to make out with any certainty, because the disease was formerly called acute hydrocephalus and no doubt deaths due to the condition which is now known as hydrocephalus were returned under the same heading. These were probably always few in number and a more serious difficulty

TABLE 5

DEATHS FROM TUBERCULOSIS: ENGLAND AND WALES: AGE-GROUPS 0-5, 5-15: 1931-35 AND 1938-43

\begin{tabular}{|c|c|c|c|c|c|c|c|c|c|c|c|c|}
\hline \multirow{3}{*}{\multicolumn{3}{|c|}{ Year }} & \multicolumn{4}{|c|}{ Respiratory } & \multicolumn{4}{|c|}{ Other } & \multicolumn{2}{|c|}{ All Forms } \\
\hline & & & \multicolumn{2}{|c|}{$0-5$} & \multicolumn{2}{|c|}{$5-15$} & \multicolumn{2}{|c|}{$0-5$} & \multicolumn{2}{|c|}{$5-15$} & \multirow{2}{*}{$\begin{array}{c}0-5 \\
M-F\end{array}$} & \multirow{2}{*}{$\begin{array}{r}5-15 \\
M--F\end{array}$} \\
\hline & & & $\mathbf{M}$ & $F$ & $\mathbf{M}$ & $\mathbf{F}$ & $\mathbf{M}$ & $\mathrm{F}$ & $\mathbf{M}$ & $\mathbf{F}$ & & \\
\hline $\begin{array}{l}1931-35 \\
1938 \\
1939 \\
1940 \\
1941 \\
1942 \\
1943\end{array}$ & $\begin{array}{l}35 \text { Aver } \\
\ldots \\
\ldots \\
\ldots \\
\ldots \\
\ldots \\
.\end{array}$ & $\begin{array}{l}\text { age } \\
\cdots \\
\cdots \\
\cdots \\
\cdots \\
\cdots\end{array}$ & $\begin{array}{r}131 \\
92 \\
79 \\
73 \\
133 \\
103 \\
127\end{array}$ & $\begin{array}{r}110 \\
61 \\
53 \\
77 \\
117 \\
96 \\
101\end{array}$ & $\begin{array}{r}182 \\
101 \\
69 \\
97 \\
112 \\
81 \\
68\end{array}$ & $\begin{array}{l}317 \\
161 \\
157 \\
182 \\
189 \\
122 \\
138\end{array}$ & $\begin{array}{l}922 \\
649 \\
596 \\
657 \\
853 \\
664 \\
629\end{array}$ & $\begin{array}{l}740 \\
569 \\
497 \\
563 \\
712 \\
535 \\
540\end{array}$ & $\begin{array}{l}517 \\
355 \\
337 \\
330 \\
418 \\
386 \\
337\end{array}$ & $\begin{array}{l}492 \\
347 \\
308 \\
327 \\
422 \\
341 \\
329\end{array}$ & $\begin{array}{l}1903 \\
1371 \\
1225 \\
1370 \\
1815 \\
1398 \\
1397\end{array}$ & $\begin{array}{r}1508 \\
964 \\
871 \\
936 \\
1141 \\
930 \\
872\end{array}$ \\
\hline
\end{tabular}




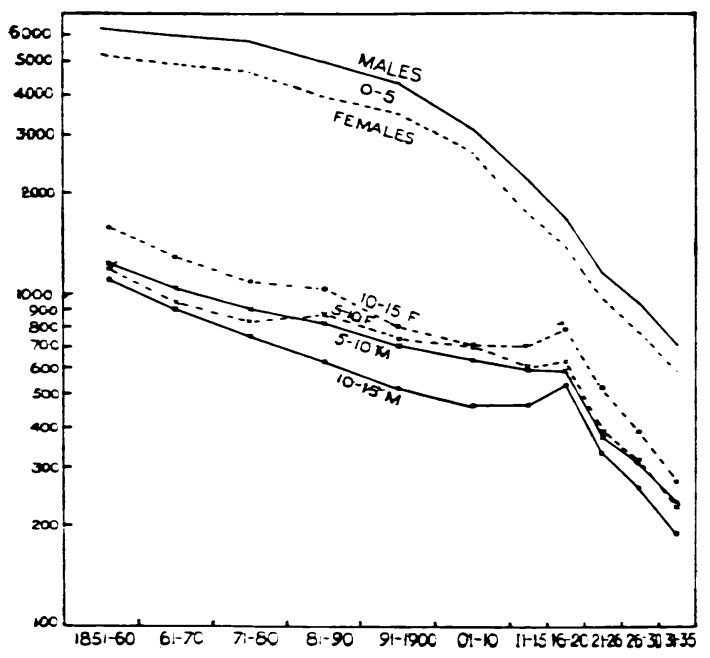

FIG. 16.-England and Wales: Tuberculosis (all forms). Death-rates per million living at various ages: Decennial periods 1851-1910, quinquennial 1911-35. Logarithmic scale.

must have been that of differentiation from other forms of meningitis, or even from a variety of other cerebral conditions. With this reservation, then, it can be said that the death-rate from tuberculous meningitis has shown a rapid and continuous decline in the age group 0-5 since 1861-70, except for the recent small rise. In the age group 5-10 the fall began about 1880 , and in the age group 10-15, which has a much lower mortality than the younger ones, in 1921-25.

The death-rates from abdominal tuberculosis have fallen rapidly among children under 10 since 1881-90, but at later ages the fall did not start until 1900 .

Tuberculosis of the bones and joints is different from other forms in that its importance is rather as a cause of crippling than as a cause of death. There is no doubt that the incidence of crippling due to tuberculosis has decreased very much, but it is difficult to give statistical evidence, because of the difficulty of defining 'crippling,' and because increased vigilance is liable to produce an apparent increase in the number of cases. Between 1921 and 1937, however, the number of deaths from tuberculosis of the bones and joints among children under 15 fell from 173 to 44 , and between 1934 and 1938 the number of children who completed treatment in residential institutions fell from 1,965 to 1,647 (Ministry of Health, 1938).

Epidemic diseases of the central nervous system. It is convenient to consider together cerebrospinal fever, acute poliomyelitis and encephalitis lethargica, usually called the epidemic diseases of the central nervous system. They have a recorded history which begins comparatively recently. They are not, in non-epidemic years, large causes of death among children or for that matter among adults. In 1938, for example, they caused 600 deaths among children under 15 compared with nearly 1,600 due to measles. 1938 was not a year of epidemic prevalence of cerebrospinal fever but was a year of rather high endemic prevalence. The graph of crude death-rates (fig. 17) gives a good idea of the course these diseases have taken. Cerebrospinal fever has had three peaks in 1915, 1931 and 1940, the last being far the highest. Encephalitis lethargica had a peak in 1921 and a higher one in 1924 and has been slowly falling since. It should be noted that the change in the method of allocation of deaths begun in 1940 has had a substantial effect in reducing the number of deaths allocated to this disease because it is often stated as a secondary cause of death and by the rules in force before 1940 it was given a high preference over other causes. Acute poliomyelitis has had several small peaks, the last and highest being in 1938 .

The relation between notification and deaths of all three diseases is interesting. In times of low prevalence the number of notifications tends to decrease more than the deaths so that the apparent fatality increases greatly. This is particularly noticeable with encephalitis lethargica. In 1937, for example, there were nearly three and a half times as many deaths as there were notifications, whereas in 1924 , there were only 18.3 deaths for every 100 notifications. There was an extraordinary rise in the apparent fatality rate of acute poliomyelitis in 1918, due partly to the fact that some deaths really due to the then 'new disease'encephalitis lethargica-were certified as polioencephalitis and partly to a reduction of notifications unaccompanied by a corresponding reduction of deaths. Cerebrospinal fever showed a few more deaths than notifications in certain years, e.g. 1928, and up to 1937 the apparent fatality rate never

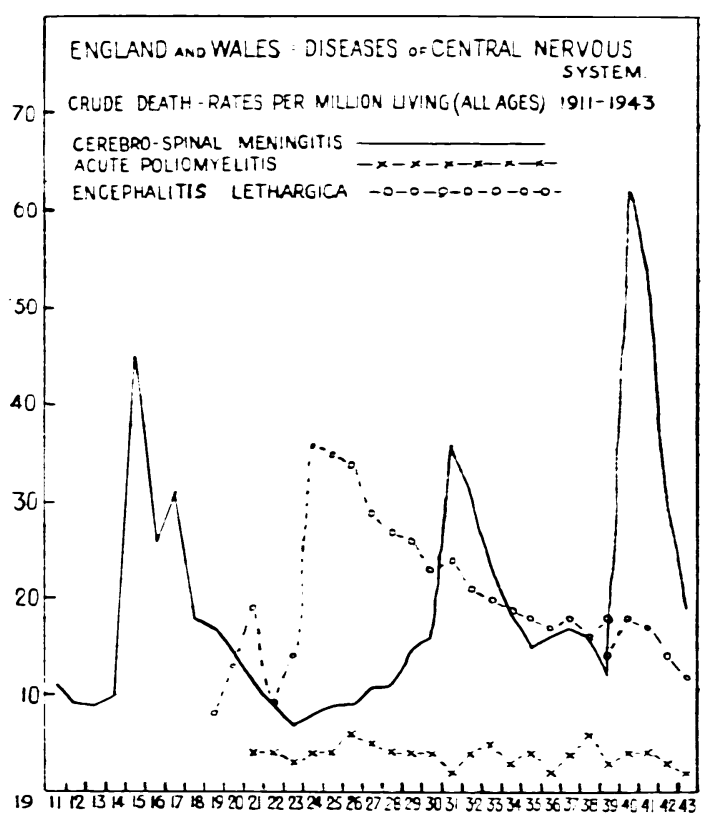

FIG. 17. 
fell below 55.6 per cent. (1933). For these reasons it is necessary to treat fatality rates, i.e. $\frac{\text { deaths }}{\text { notifications }}$, with some reserve, but the recent history of cerebrospinal fever does suggest a real and very substantial fall in fatality:-

TABLE 6

\section{RECENT FATALITY RATES OF CEREBRO- SPINAL FEVER}

1937
1938

$\begin{array}{ccc} & & \text { Per cent } \\ \ldots & \ldots & 61.2 \\ \ldots & \ldots & 50.6\end{array}$

1939

1940

1941

1942

1943

\begin{tabular}{llc} 
& \multicolumn{2}{c}{ Civilians } \\
$\ldots$ & $\ldots$ & 36 \\
$\ldots$ & $\ldots$ & 22 \\
$\ldots$ & $\ldots$ & 21 \\
$\ldots$ & $\ldots$ & 22 \\
.. &. & 25
\end{tabular}

Non-civilians
16
8
8
8
10

It seems certain that this great reduction has been Gue to the introduction of the sulphonamides. The importance of the epidemic of 1940 may be judged by the fact that in 1940 there were 1,343 (1941-1125) deaths from cerebrospinal fever among children under 15 compared with 425 in 1938 and 310 in 1939.

All these diseases are important causes of disability. It is impossible to give any reliable statistics of the numbers crippled by them but every cripple school and every hospital and orthopaedic clinic has its quota of cases due to acute poliomyelitis and every school for the deaf has a number of children deafened by cerebrospinal fever. The child victims of encephalitis lethargica, though few in number, are among the most pathetic of all, for the mental changes cause distress to themselves and their families and they are extremely difficult to look after.

Diseases of the nervous system and sense organs. The epidemic diseases of the nervous system are not now included by the Registrar-General under the general heading of diseases of the nervous system and sense organs but under the general heading of 'Epidemic Diseases.' It is probable, however, that the actual transfer of deaths from one heading to the other has been a gradual process dependent on the growth of medical knowledge of the diseases and the spread of that knowledge among the general practitioners of the country. Cerebro-spinal fever deaths were first returned under that separate head in 1869 , but the death-rates given in table 9 of the Registrar-General's Annual Review begin in 1911. Death-rates for acute poliomyelitis also date from 1911 and those from encephalitis lethargica from 1921.

At the present time deaths among children returned under the main heading 'diseases of the nervous system and sense organs' fall chiefly under three sub-headings-convulsions, meningitis (not including meningococcal or tuberculous meningitis) and diseases of the ear and mastoid sinus. In 1938, 2,584 of the total of 51,986 deaths which occurred in children under 15 were allocated to the main heading-864 of these to convulsions, 534 to meningitis and 649 to diseases of the ear and mastoid.
'Convulsions' is, of course, much more commonly stated as the cause of death in infants than in older children. Both convulsions and meningitis are indefinite causes and have been gradually disappearing from the returns as certification has improved. In the age group 1-5, for example, the death-rate from 'convulsions' per million living in 1911-14 was 460 and in 1937 it was 53, that of 'meningitis' was 451 in 1911-14 and 88 in 1937. When considering the trend of death-rates in childhood over a long period it is necessary to bear in mind this kind of effect because it is likely that the death-rates from common infectious diseases and respiratory infections were substantially understated in the earlier part of the period, particularly among infants, a large number of deaths being ascribed to this indefinite cause 'convulsions.' The deaths in children from diseases of the ear and mastoid rose in the early thirties to a maximum in 1934 and have since declined in much the same way that other streptococcal diseases have (fig. 14).

It is impossible to give a satisfactory picture of the course of these, even now, ill-defined diseases of the nervous system over the whole period because of the great changes in medical knowledge about them, but it is of interest to recall that in 1861-70 the average yearly number of deaths among children under 15 ascribed to brain diseases was 31,474 and in 1938 2,584 were ascribed to diseases of the nervous system and sense organs and another 515 to epidemic diseases of the central nervous system making 3,099 in all. These figures are not strictly comparable one with another but they serve to show what remarkable reductions have taken place in the mortality not only of the well-defined diseases which are commonly studied but also in the mortality of those conditions which, because they are illdefined, are seldom studied.

Intestimal infections. In that part of table 2 which compares infant mortality in 1873-75 with that in 1931-35, excluding congenital causes, diarrhoea was third in the early table and second in the later one, but whereas in 1873-75 the rate was $17 \cdot 1$ per 1,000 births in $1931-35$ it was $5 \cdot 4$. Fig. 18 shows how infant mortality from this cause has varied since 1885 and what relation it has had to the total rate. The last great epidemic associated with a hot summer was in 1911 and after 1915 the rate fell very considerably. There was a small and sudden rise in 1921, associated with a hot summer, but since then the rate has hardly varied from year to year and has gone down slowly from about 6.5 to just under 5.0 per 1,000 births against the rates of 30 per 1,000 which were usual in hot summers before the last war. Another feature of this disease has been the shift in mortality from the hot months of late summer to the winter months. The cause of this summer diarrhoea of infants is unknown, but from its epidemiological history it looks almost as though a disease had disappeared in the last war, except for a dying spurt of activity in 1921, and that the infantile diarrhoea of the present day, with its steady death-rate and its higher incidence in 


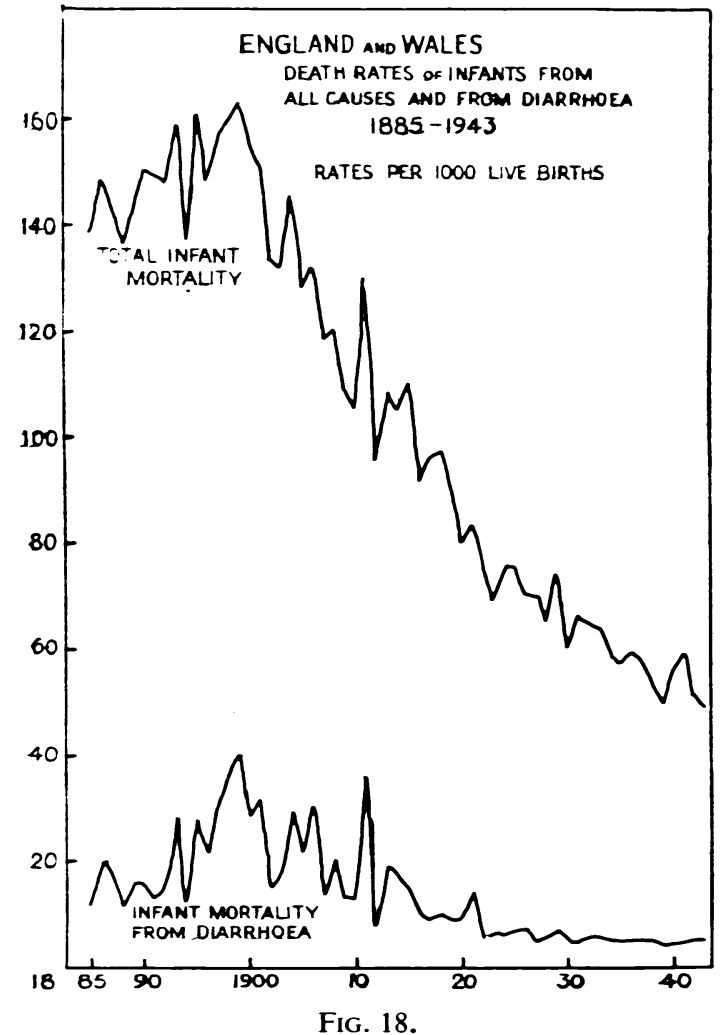

winter may have a different causation. Since 1940 enteritis deaths under two years have increased a little in the March and June quarters, but there is no sign of a return to the position of 35 years ago and it must be remembered that the population at risk has increased. The mortality rates among infants under one year during the war years have been :-1940, 4.4; 1941, 4.7; 1942, 5.0; 1943, 4.9 per 1.000 live births.

When the intestinal infections of older children are considered it is found that formerly epidemic diarrhoea and enteritis took a toll from the age group 1-5 though to nothing like the same extent as among infants. The death-rate per million living in the age group 1-5 in 1861-70 was 193 and it ranked eighth, next below diphtheria and croup. Immediately below comes typhus, which heading then included the typhoid group, and this becomes a more important cause in the older age groupsthird in the age group 5-10 and second in the age group 10-15. The typhoid group was not separated from typhus until 1869. Greenwood (1935) describes the subsequent course of the standardized death-rate at all ages as follows:-

' Roughly from 1875 over the next ten years there is a rapid fall, then rather more than a decennium showing little change. At the beginning of the twentieth century another rapid fall began which slackened into a gentle descent which has continued fairly regularly since about 1910 . The reader should remember that the eternal difficulty of comparability between diagnosed causes of death at different epochs probably tells against us and makes the general decline less impressive than it really is, because typhoid is now more freely diagnosed.'

Typhus has now disappeared in this country except for occasional isolated cases in the ports and the enteric group has decreased so much that in 1938 there were only 15 deaths in England and Wales in the whole age group 0-15.

In 1861-70 there were deaths from cholera in epidemic years more particularly in the later years of childhood. The last serious epidemic of this disease in England and Wales was in 1865-66 though there was danger in 1871 when the disease reached Russia and the North German ports.

The great reduction in intestinal infections as causes of death in childhood is generally considered to be the most obvious triumph of sanitary measures and this seems a reasonable explanation so far as the typhoid group and cholera are concerned, but it does not explain the behaviour of epidemic diarrhoea of infants.

Appendicitis. Mention should be made of appendicitis which caused 518 deaths among children under 15 in 1938. Between 1911-20 and 1932-34 there was no appreciable change in the standardized mortality at all ages, but there was definite evidence of postponement of death to later ages. Since 1931-35 there has been a further fall in the deathrate among young children from 67 per million in the age group 1-5 to 56 per million in 1939 and 39 per million in 1942 (Stocks, 1943). It is not clear whether this recent fall is due to a continuation of the process which was going on before or to improved methods of treatment.

Handicapped children. It would be impossible to give any general account of the part played by infections in causing disability of all degrees because these are so variable, but perhaps some rather random observations on the changes which have affected the importance of infections as causes of the major permanent disabilities may be of interest.

1. Blindness. Kerr (1926) states that at the time of his first survey of the London Schools for blind children in 1903, 42 per cent. of the cases were assigned to ophthalmia neonatorum. In 1921 Bishop Harman found that about 20 per cent. of cases were due to ophthalmia neonatorum and about 21 per cent. were due to interstitial keratitis. In 1938 only 14 of 100 children in the London County Councils blind schools had been blinded by ophthalmia neonatorum and only one as a result of interstitial keratitis. Evans (1943) in a recent paper on ophthalmia neonatorum in Birmingham says that there has been only one case of blindness from this cause in the last seven years. These figures must be accepted with some reserve because it is often difficult to determine the cause of blindness from the history, but there is no doubt that there has been an enormous reduction in the number of cases due to venereal disease.

2. DEAFNESS. The great reductions of the severity 
of the common infectious diseases have undoubtedly led to remarkable reductions in the number of severe cases of middle ear deafness. In an old admission register of a large school for the deaf recently examined by the author the entries during the 'seventies included a high proportion of cases due to scarlet fever and other common infectious diseases, but in the same school in 1943, there was not one case of active otitis media among 127 children. That school is probably exceptional, but there is no doubt of the enormous reduction. There is one infection, however, which is still a matter of serious concern, namely cerebrospinal meningitis, and it may be that the introduction of the sulphonamides, by reducing mortality, may indirectly increase the number of cases of deafness. Many heads of schools for the deaf have commented on the large proportions of recent admissions of children deafened by this disease, and a small preliminary investigation has been carried out by the author (Gale, 1944) which suggests an increase in the number of cases due to the disease.

Comment has already been made on the reductions of crippling by tuberculosis of bones and joints and of that due to rheumatic heart disease.

\section{Association of bad social conditions with high child mortality}

It is not, of course, a new cbservation that high death-rates, particularly in childhood, are closely associated with bad social conditions. This is what Farr has to say on the subject in the supplement to the 25th Annual Report of the Registrar-General covering the years $1851-60$.

- There is no doubt great negligence on the part of the parents, great ignorance of the conditions on which health depends and great privation among the masses of the poor, but there is no reason to suspect that any great number of the infants in these districts fall victims to deliberate crime; yet the children of the idolatrous tribe who passed them through the fire to Moloch scarcely incurred more danger than is incurred by the children born in several districts of our large cities.'

In the supplement to the 25 th report he compared the death-rates of children aged 0-5 living in 28 rural areas with the death-rates in certain great towns and found that whereas Bellingham, a rural district in Northumberland, had a death-rate of 2.3 per cent. in this age group, Liverpool had a rate of 13.2 per cent. In the Supplement to the 35 th Annual Report Farr gave a table comparing the numbers of children dying under age 5 in the - Healthy Districts' in ' England ' and in 'Liverpool' and the causes of their deaths. Table 7 is an extract from this.

It was not only in cities that mortality was high and there is an interesting sidelight on infant mortality in the rural fen country in Simon's report to the Privy Council for 1863. It had been found that infant mortality in some of the fen districts, e.g. Wisbech, King`s Lynn, was nearly as high as it was in the great cities, being of the order of 220-270 per 1,000 births. Dr. H. J. Hunter was sent to investigate and found that the high rate was chiefly due to maternal neglect owing to the fact that women were extensively employed in gang labour in the fields. In order to quieten the infants left behind at home it was usual to dose them heavily with an unholy brew known as 'Godfrey's cordial which consisted of opium, treacle and oil of sassafras. The wages paid to these women working in agriculture ranged from $8 \mathrm{~d}$. to $1 \mathrm{~s}$. 8d. per day.

\section{TABLE 7}

OF 10,000 CHILDREN BORN THE NLMBER DYING UNDER THE AGE OF FIVE IN 1861-70:--

\begin{tabular}{|c|c|c|c|}
\hline Cause & $\begin{array}{l}\text { Healthy } \\
\text { Districts }\end{array}$ & England & $\begin{array}{l}\text { Liver- } \\
\text { pool }\end{array}$ \\
\hline $\begin{array}{l}\text { Zymotics } \\
\text { Tuberculosis (all forms) } \\
\text { Diseases of the brain.. } \\
\text { Diseases of the lungs.. } \\
\text { Other .. . } \quad \text {. }\end{array}$ & $\begin{array}{l}498 \\
146 \\
227 \\
279 \\
604\end{array}$ & $\begin{array}{l}871 \\
219 \\
401 \\
415 \\
726\end{array}$ & $\begin{array}{r}1,710 \\
318 \\
498 \\
799 \\
1,279\end{array}$ \\
\hline All causes & 1,754 & 2,632 & 4,604 \\
\hline
\end{tabular}

N.B.-Farr's ' Healthy Districts were the 51 registration districts of England and Wales which had the lowest general death-rates for years 1861-70,17 per 1,000 and under.

Since Farr's time many investigations have been made and the problem is chiefly one of selection from a wealth of material. The earlier investigations were designed chiefly to point out the great differences obtaining in different areas. and the detailed reports on infant and on child mortality produced by the Chief Medical Officer of the Local Government Board between 1911 and 1917 are good examples. More recently attempts have been made to determine the relative importance of different social factors, but this is by no means easy because the different factors are usually so closely associated that it is difficult to isolate them. For example, bad and overcrowded housing conditions are usually associated with low incomes and large families.

The parts of the Decennial Supplements of the Registrar-General for 1911, 1921 and particularly that for 1931, which deal with Occupational Mortality give direct information on the influence of social class on the mortality of infants. for in addition to giving the mortality figures of men in different occupations, they give mortality figures of infants for different occupations of the father and for various important causes of death. The supplement for 1931 based on the mortality experience of the years 1930-32 also gives the death-rates of legitimate children in the age group 1-2 classified according to the father's occupation and for several important causes. In the summary tables the occupations of the father are classified into five great social classes. Broadly speaking, class I consists of those engaged in 
the professions, class III of skilled workers and class V of unskilled and casual workers, classes II and IV being intermediate groups. It is not easy to select from the wealth of information given in this Report but the facts about the relative mortality from all causes in the different classes among infants and among children in the age group 1-2 for the years 1930-32 were (table 8):-

TABLE 8

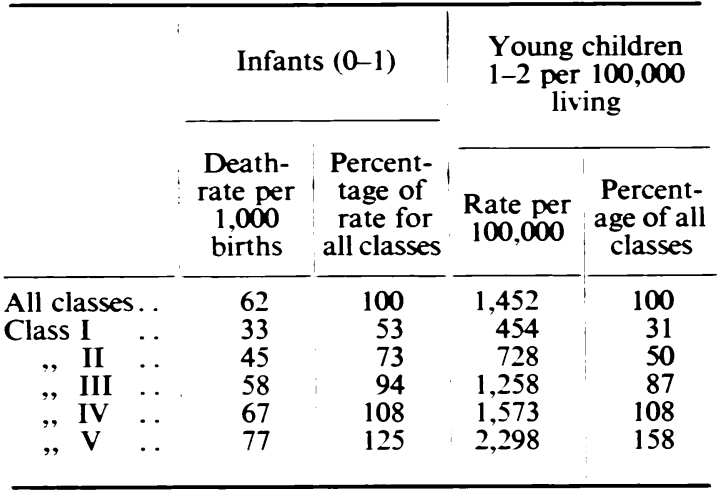

It will be seen that the difference between the classes increases with age and in a more detailed analysis of mortality at different stages of the first year this effect is shown in greater detail.

TABLE 9

ENGLAND AND WALES: 1931-32. DEATHRATES AT DIFFERENT STAGES OF FIRST YEAR OF LIFE IN DIFFERENT SOCIAL CLASSES: RATES EXPRESSED AS PERCENTAGE OF THAT FOR ALL CLASSES TOGETHER

\begin{tabular}{|c|c|c|c|c|c|c|}
\hline & $\begin{array}{l}0-4 \\
\text { wk. }\end{array}$ & $\begin{array}{l}4 \text { wk. } \\
\text { to } 3 \\
\text { mth. }\end{array}$ & $\begin{array}{l}3-6 \\
\text { mth. }\end{array}$ & $\begin{array}{l}6-9 \\
\text { mth. }\end{array}$ & $\begin{array}{l}9-12 \\
\text { mth. }\end{array}$ & $\begin{array}{l}1-2 \\
\text { yr. }\end{array}$ \\
\hline All classes & 100 & 100 & 100 & 100 & 100 & 100 \\
\hline $\begin{array}{cll}\text { Class } & \text { I } & \ldots \\
,, & \text { II } & \ldots \\
, & \text { III } & \ldots \\
,, & \text { IV } & \ldots \\
, & \text { V } & \ldots\end{array}$ & $\begin{array}{r}72 \\
90 \\
97 \\
106 \\
108\end{array}$ & $\begin{array}{r}43 \\
65 \\
93 \\
108 \\
131\end{array}$ & $\begin{array}{r}37 \\
56 \\
89 \\
112 \\
143\end{array}$ & $\begin{array}{r}28 \\
52 \\
87 \\
113 \\
148\end{array}$ & $\begin{array}{r}28 \\
49 \\
87 \\
113 \\
151\end{array}$ & $\begin{array}{r}31 \\
50 \\
87 \\
108 \\
158\end{array}$ \\
\hline
\end{tabular}

Deaths occuring in the first four weeks of life are usually due to conditions peculiar to early infancy whereas those occurring in infants between four weeks and the first birthday are usually due to much the same infections as those which kill older children. Neonatal mortality (under four weeks), therefore, gives an index of the death-rates of conditions such as prematurity, birth injuries and so on, whereas the rates from four weeks to one year give an index of the behaviour of infections. This distinction is not of course absolute, but it is useful.

When death-rates from individual causes in the first year are considered it is found that on the whole death-rates from conditions peculiar to early infancy show much less increase from class $I$ to class $\mathbf{V}$ than do the infections. During the second year of life measles, whooping-cough, bronchitis and pneumonia show the steepest social gradient but all the other infections examined show some variation (table 10).

In the Annual Review (Text) for 1934 the Registrar-General examined the possibility that high child mortality from measles and whoopingcough might be affected considerably by climate. He concluded that mere northerliness of situation when divorced from its accompanying increased housing density had no important effect on measles mortality and the same was broadly speaking true of whooping-cough.

The detailed study of mortality by social class is possible only for the years round about a census year and for intermediate years the less direct method of comparison between areas in which the general social conditions are known to differ markedly is often used. One of the social indices generally used is that of housing, and it may perhaps be desirable to point out here that the index of density of population per acre which was used by Farr is not of much value now. because people living in large blocks of luxury flats may be living at a higher density per acre than those living in small houses in a slum. The more usual index now is that of average number of persons per room. In the Registrar-General's Annual Review (Text) for 1937 there is an interesting comparison of mortality 
rates of infants at different stages of the first year of life in the years 1933-37 in certain of the county boroughs which have widely different social conditions. The comparison brings out very clearly the point made earlier that the rates of early infancy are but little affected by social conditions in comparison with those of later infancy. Stocks (1944b) has shown that between 1938 and 1942 the total infant mortality rate in Greater London has fluctuated between 43.7 in 1939 and 52.1 in 1941 , whereas that of New York has shown a continuous fall from 38.3 in 1938 to 28.8 in 1942 . The neonatal rates of the two great cities are not very different-Greater London 24.9 in 1942 and New York 21.0-but New York has a great advantage over Greater London in respect of its rate for infants between four weeks and one year. In 1942 that of Greater London was 21.7 and that of New York 7.8. This advantage was present before the war but is now greater than it was then.

In addition to the information on the effect of social conditions on child mortality contained in the Registrar-General's and other official reports a great deal of work has been done by individual workers.

Wright and Wright (1942) investigated the morbidity and mortality of children under five from diphtheria, measles, tuberculosis and whoopingcough in the metropolitan boroughs between 1931 and 1938, and worked out correlation coefficients between morbidity and mortality and various indices of social conditions. One of their conclusions is that, for diphtheria, morbidity is perhaps more closely associated with bad housing than is mortality and in this connexion it is interesting to recall how rare diphtheria was in the public schools investigated by the Schools Epidemics Committee (1938). Only twelve cases were reported from the public schools with an average population of over 8,000 , whereas there were twenty-six cases in one of the naval schools-the subjects of Dudley's (Dudley, 1926; Dudley et al., 1934) classical investigations-with an average termly population of 881 . It should be noted, however, that the boys in the naval school were on the average several years younger than boys in public schools. R. E. Smith (1935) found that of 513 boys who left Rugby between 1931 and 1935 fourteen (2.7 per cent.) had had diphtheria, 55 (11 per cent.) scarlet fever, 382 (74 per cent.) whooping-cough and 493 (96 per cent.) measles. Stocks (1942; Stocks and Karn, 1928) estimates that at least 90 per cent. of London children have a recognizable attack of measles before they are 15 but that in England and Wales as a whole the proportion is probably below 80 per cent. His estimate of the proportion of children who have had whooping-cough before age 15 is 60 per cent. for London (Stocks and Karn, 1932) and something under 40 per cent. for the country as a whole (Stocks, 1942). Among earlier papers on the influence of social conditions on morbidity and mortality from the common infections in childhood should be mentioned those of C. M. Smith (1927, 1934) and Halliday (1928) on their work in Glasgow. They concluded that the high death-rates of children from infections in the over- crowded tenements were due chiefly to high incidence and to the early age at which the children were infected.

The facts which have been given about the association between morbidity and mortality in childhood and bad social conditions are mere oases of knowledge in a desert of ignorance, and it seems doubtful if great progress can be expected until more information is available about morbidity. Perhaps this may be forthcoming in the future on the lines suggested by Stocks (1944c). It is, however, certain that social conditions are of great importance in determining mortality, and it seems probable that the total incidence of some diseases, e.g. diphtheria, is different in different classes, whereas others, e.g. measles, have a similar incidence in all classes, if children of all ages are considered, but tend to occur earlier in children living under poor home conditions. It has been shown that the differences of mortality between different classes are not nearly so noticeable in the first month of life as they are in later infancy and early childhood, facts which suggest that nurture is more important than nature in determining mortality rates in children.

\section{Child mortality in relation to social history}

'How then is the tale to be told? Into what periods shall social history be divided up? As we look back on it, we see a continuous stream of life, with gradual change perpetually taking place, but with few catastrophes. The Black Death is perhaps one, and the Industrial Revolution another. But the Industrial Revolution is spread over too many generations to be rightly regarded either as a catastrophe or as an event. It is not, like the Black Death, a fortuitous obstruction fallen across the river of life and temporarily diverting it; it is the river of life itself in the lower part of its course.' Trevelyan (1944).

The changes described in this paper are a small but not unimportant part of the changes associated with the Industrial Revolution, and it is therefore of interest to speculate on the possible relations between the trends of death-rates in childhood and the general social history of the period. First, however, it is necessary to go back further than the beginning of the statistical era (1837) because by then the Industrial Revolution was in full flood and it is impossible to assess the damage or the good caused by that flood without a brief survey of the state of affairs at its beginning.

C. Buer (1926) in her book on the early days of the Industrial Revolution points out that although the statistical data of the period 1760-1815 are imperfect it is certain that the population of England and Wales was increasing at a phenomenal rate in those years, from about six million in 1750 to about ten million in 1811 , and reasonably certain that the increase was due much more to a reduction of mortality, particularly among children, than to any increase in the birth-rate. She suggests that the 
main causes of this reduction in mortality were improvements in agriculture which to a large extent abolished the dangers of periodic famine, elementary improvements in housing and the sanitation of towns. improvements in medical care and the reduction in the mortality of smallpox. Farr (1885) quotes figures based on the London bills of mortality which are of interest as an indication of the reduction in child mortality which took place in London in the eighteenth and early nineteenth centuries:-

TABLE 11

TABLE: BIRTHS AND DEATHS LNDER 5 ACCORDING TO THE LONDON BILLS

\begin{tabular}{|c|c|c|c|c|c|}
\hline Years & $1730-49$ & $1750-69$ & $1770-89$ & $\begin{array}{l}1790- \\
1809\end{array}$ & $1810-29$ \\
\hline $\begin{array}{l}\text { Total births } \\
\text { Deaths under } 5 . \\
\text { Percentage dving }\end{array}$ & $\begin{array}{l}315.456 \\
235.087\end{array}$ & $\begin{array}{l}307.395 \\
193.694\end{array}$ & $\begin{array}{l}349.477 \\
180.058\end{array}$ & $\begin{array}{l}386.393 \\
159.571\end{array}$ & $\begin{array}{l}477.910 \\
151.794\end{array}$ \\
\hline under 5 & $74 \cdot 5$ & $63 \cdot 0$ & $51 \cdot 5$ & $41 \cdot 3$ & $31 \cdot 8$ \\
\hline
\end{tabular}

Farr (1885) also gives the following figures for deathrates in children for the period 1813-30 :-

TABLE 12

DEATH-RATES PER 1,000 LIVING 1813-30 AND 1841-50

\begin{tabular}{|c|c|c|c|c|c|c|}
\hline \multirow[b]{2}{*}{ England and $\mathbf{W}$ ales } & \multicolumn{2}{|c|}{$0-5$} & \multicolumn{2}{|c|}{$5-10$} & \multicolumn{2}{|c|}{$10-15$} \\
\hline & $\underset{53 \cdot 5}{M 1}$ & $\stackrel{F}{46 \cdot 0}$ & $\begin{array}{l}\text { MI } \\
7 \cdot 2\end{array}$ & $\underset{6.7}{F}$ & $\begin{array}{l}M \\
5 \cdot 0\end{array}$ & $\begin{array}{l}F \\
5 \cdot 2\end{array}$ \\
\hline $\begin{array}{l}\text { England and Wales, } \\
1841-50 \text { (table 1) }\end{array}$ & $71 \cdot 2$ & 61.6 & $9 \cdot 2$ & 8.9 & $5 \cdot 1$ & $5 \cdot 4$ \\
\hline
\end{tabular}

These figures, which must be accepted with reserve, are, for England and Wales as a whole, lower than those of 1841-50. Probably the early figures are an underestimate but it is likely that the death-rates of children were rising slightly in the early part of the nineteenth century because of the growth of the towns. There were, in fact, two great opposing influences at work throughout the nineteenth century. The one which tended to lower death-rates was the slow improvement in the condition of the working classes, and the other which tended to increase them was the exodus from the country where conditions were relatively favourable, to the towns where conditions were appalling. The bad conditions in towns were, however, not new. The London of Hogarth's 'Gin Lane' was not a healthier place than the London described in Simon`s (1890) book and in his annual reports, but it was much smaller. This factor of rapid growth was, of course, even more important in the industrial towns. When the statistical era is considered it can still be seen that two influences are at work, for infant mortality and the death-rate $0-5$ did not fall at all in the first twenty years of registration, whereas those for 5-10 and 10-15 were falling slowly (fig. 2). An influence which acted favourably and selectively on the older age groups was the slow improvement in industrial conditions and the change in the status of the child from that of wage-earner in the factory to that of future citizen in the school (Robson, 1931). Infant mortality did not really begin to fall until the beginning of the 20th century, but the rate 1-5 had been falling since 1861-70. From 1870 improvements in the sanitation of the towns were accelerated and became more effective. In the period 1900-14 the rates fell in all age groups, but the fall in the age groups 5-10 and 10-15 was arrested in the last war and the rates rose a little in the quinquennium 1916-20 chiefly because of the epidemic of influenza in 1918. The period between 1900 and the beginning of the last war was that in which the modern personal health services began. The school medical service was started in some areas in the early years of the century and was made universal in 1907. The first infant welfare centre was established in Marylebone in 1907. The public tuberculosis service began in 1911. According to Cole and Postgate (1938) real wages were rather lower in 1914 than at the beginning of the century.

Between the wars the decline of death-rates of children has been particularly rapid in the age group $1-5$, and recently, from 1935 to the present time, all the rates have been falling faster than before. The inter-war period has been one of continued development of the personal health services, one of rapid reduction in the average size of families and on the whole one of increases in real wages (Cole and Postgate, 1938) and in the standard of living generally. It may be that the introduction of the sulphonamides has contributed materially to the recent declines and in the last two or three years the widespread practice of active immunization against diphtheria has been important.

\section{The history of individual diseases}

If the history of child mortality is approached from a different point of view-that of the history of individual diseases-it is found that smallpox was easily the most deadly identifiable disease of young children up to the end of the eighteenth century when it began to wane and to become more a disease of adolescents and of adults. Stevenson and Murphy (1893) give an interesting diagram, based on the London Bills, of the relative importance of smallpox, measles and whooping-cough as causes of death at all ages between 1740 and 1890 . The peak year for smallpox on this diagram was 1796 when 186 of every 1,000 deaths at all ages recorded in the Bills were due to smallpox. Measles and whooping-cough caused a substantial number in epidemic years-for each disease between 30 and 50 of every 1,000 deaths recorded at all ages. These figures from the Bills are, of course, of doubtful accuracy. How far the reduction in and change in age distribution of mortality from smallpox was due to the introduction of vaccination in 1798 is a controversial problem. Greenwood (1935) is doubtful whether vaccination was sufficiently widely practised to exert an epidemiological effect and Burnet (1940), whilst conceding some influence to vaccination, considers that the natural evolution of 
the disease was the most important factor. At the beginning of the statistical era scarlet fever, which had been increasing in virulence since about 1825 , was already a great killing disease though it reached its peak in 1863 with a death-rate of 3,966 per million living under 15 . In the eighties and 'nineties the mortality of scarlet fever declined rapidly, and this fact accounts to a considerable extent for the reduction in the general death-rates at ages 1-5, 5-10, 10-15 (fig. 2). The behaviour of scarlet fever, which is generally ascribed to change of type, has never been more adequately explained, and it would be interesting to re-examine the problem in the light of modern knowledge of its bacteriology. Smallpox and scarlet fever showed the most dramatic changes in the nineteenth century and the behaviour of the other important infections is sufficiently summarized in fig. $5,6,12,16,18$.

With the beginning of the twentieth century an all round reduction of death-rates in childhood began, particularly of infant mortality. The mortality of bronchitis and pneumonia began to fall and the decline of tuberculosis, diphtheria and whooping-cough was accelerated. Measles deathrates did not begin to fall until the quinquennium 1916-20. The rise in tuberculosis in the last war and the influenza epidemic of 1918 interrupted the general downward tendency of the general deathrates except that of infants. Since 1918 almost every infection has shown more rapid declines of mortality than ever before except that diphtheria showed no consistent decline until recently. The declines of the mortality of measles since 1915 and of that of summer diarrhoea since 1911 have been almost as sudden and remarkable as that of scarlet fever in the 'eighties and 'nineties. Naturally the big question is whether these are changes of type which may be reversible. On the whole, the fact that declines have occurred in the mortality of other diseases-whooping-cough, bronchitis and pneumonia and tuberculosis-gives ground for hope that improvements are likely to continue provided that social conditions continue to improve. Since about 1935 the sulphonamides may have been an important influence, but it is difficult to be sure of this because streptococcal activity was falling between 1934 and 1941 (fig. 14). It is suggested that from 1915 to the present time the factor of reduction of ' family density " has been particularly important.

\section{Conclusions}

A survey such as this of the whole field of infections in childhood over many years is a wholesome corrective to cynicism, but the great differences which still exist in different places and in different social classes are a stimulus to further research and action. It has been possible to sketch only a background for the study of social medicine in childhood and even that background has many blank spacesnotably in those parts which picture the incidence of disease rather than mortality. The study is offered in the hope that it may be of some use to those who try to solve the many problems of the prevention or cure of individual diseases.

Thanks are due for the help received from Professor M. Greenwood, Dr. W. J. Martin, Dr. P. Stocks, Dr. J. A. Glover, Dr. W. H. Bradley and Dr. J. A. H. Brincker.

\section{Figures and Tables: Sources of Figures}

Fig. 1.-Census Report, 1931; R.G. Dec. Supplement, Part III, 1921: R.G. Ann. Rev. (Tables Med.), 1939.

Fig. 2.-R.G. Ann. Rev. (Tables Med.), 1940. Tab. 5; Ann. Rep. C.M.O., Min. of Health, 1933, p. 26.

Fig. 4.-Ann. Repts. C.M.O., Bd. of Education, 1929-38; Stocks (1944).

Fig. 5.-R.G. Ann. Rev. (Tables Med.), 1940. Tab. 9. Fig. 6.-R.G. Dec. Supplement, 1921, Part III; Figures 1921-30, supplied by Dr. P. Stocks. Rates for 1938-39 calculated from R.G. Ann. Rev. (Tables Med.), Tables 1 and 21.

Fig. 7.-1911-14, R.G. Ann. Rev. (Text). Table XXXIII: 1915, calculated from R.G. Ann. Rept.; 1916-20, R.G. Ann. Revs., 1921-37. R.G. Ann. Rev. (Text), 1937, Table XXXIV: Stocks (1943).

Fig. 8.-Tuberculosis Ann. Repts. C.M.O.. Bd. of Education, 1929-38. Other diseases, see under fig. 7 .

Fig. 9.-Death-rates R.G. Ann. Rev. (Tables Med.), Table 9: Notification rates R.G. Ann. Rev. (Tables Med.), 1921, 1931, 1939: Table 26. Rates after 1939 from Min. of Health, Summary Repts. and R.G. Quarterly returns. Case fatality, 1911-37, R.G. Ann. Rev. (Text), 1937, Table XLII.

Fig. 10.-R.G. Weekly and Quarterly returns, 1938-44.

Fig. 11.-See under fig. 7.

Fig. 12.-See under fig. 6.

Fig. 13.-Bronchitis and pneumonia 1-5, see under fig. 7: Pneumonia and Influenza Ann. Rev. (Tables Med.) Table 7, 1921, 1929, 1939: Recent rates Summary Repts., Min. of Health and R.G. Quarterly returns (based on 1939 pop.).

Fig. 14.-See under fig. 13.

Fig. 15.-Ann. Repts. C.M.O., Bd. of Education, 1928-38. Recent figures supplied by Dr. P. Stocks.

Fig. 16.-R.G. Ann. Rev. (Text), 1935; Table I.

Fig. 17.-See under fig. 13.

Fig. 18.-Ann. Rep. C.M.O., Min. of Health. 1919-20, p. 26: R.G. Ann. Rev. (Tables Med.), 1929, 1939; Table 12.

Table 1.-R.G. Ann. Rev. (Tables Med.), 1940: Ann. Rep. C.M.O., Min. of Health, 1933, p. 26: Stocks $(1943,1944 a)$

Table 2.-Inf. Mort., 1873-75, R.G. 39th Ann. Rept.: R.G. Ann. Rev. (Text), 1939, Table XXIII. Later Childhood, Ann. Rep. C.M.O., Min. of Health. 1938, p. 23: R.G. Supplement to 35th Ann. Rept.: R.G. Dec. Supp. 1921, Part III.

Table 3.-Stocks (1943).

Table 4.-Russell (1943), p. 12.

Table 5.-Med. Res. Council Special Report Series, No. 246 , p. 32.

Table 6.-R.G. Quarterly Returns.

Table 7.-R.G. Supplement to 35th Ann. Rept., p. xxix.

Tables 8, 9, 10.-R.G. Decennial Supplement, 1931, Part IIA, pp. 163-167.

Table 11.-Farr (1885), p. 195.

Table 12.-Farr (1885), p. 181.

\section{REFERENCES}

Allison, V. D. (1942). Control of common fevers, Lond., p. 57.

Bishop Harman, N. (1921), Brit. med. J., 2, 727.

Brincker, J. A. H. (1938). Proc. roy. Soc. Med.. 31, 807. Buer, C. (1926). Health, wealth and population, 1760 1815 , Lond., p. 23.

Burnet, F. M. (1940). Biological aspects of infectious disease, Camb., p. 299. 
Cheeseman, E. A., Martin, W. J., and Russell, W. T. (1939). J. Hyg., Camb., 39, 181.

Cole, G. D. H., and Postgate, R. (1938). The common people, Lond., p. 616.

Dudley, S. F. (1926). Med. Res. Council, Special Report Series, No. 111.

__, May, P. M., and O'Flynn, J. A. (1934). Ibid., No. 195.

Evans, P. J. (1943). Lancet, 2, 334.

Farr, W. (1885). Vital statistics, Lond.

Gale, A. H. (1944). Min. of Health Bulletin, 4, 164.

Glover, J. A. (1930). Lancet, 1, 499.

- (1943). Ibid., 2, 51.

Greenwood, M. (1935). Epidemics and crowd diseases, Lond.

Halliday, J. L. (1928). Med. Res. Council, Special Report Series, No. 120.

Kerr. J. (1926). The fundamentals of school health, Lond.

Liverpool (1938). Annual Report of Med. Officer of Health.

Local Government Board (1915-16). Supplement to Ann. Rept. of Chief Med. Officer.

London County Council (1927-28). Special Reports by. the Med. Officer of Health on Measles Epidemic. Also reports for years 1929-30: 1931-32; 1933-34: 1935-36.

Med. Research Council (1942). Special Report Series, No. 246.
Ministry of Health (1938). Ann. Rept. of Chief Med. Officer, p. 138.

Ministry of Health (1944). Monthly Bulletin, 3, 142.

Privy Council (1859-63). Ann. Rept. of Med. Officer.

Robson, A. H. (1931). The education of children engaged in industry, 1833-76, Lond.

Russell, W. T. (1943). Med. Res. Council Special Report Series, No. 247.

Schools Epidemics Committee (1938). Ibid., No. 227.

Simon, J. (1890). English sanitary institutions, Lond.

Smith, C. M. (1927-28). J. Hig., Camb., 27, 328. (1934). Med. Res. Council, Special Report Series, No. 192.

Smith, R. E. (1935). Practitioner, 135, 283.

Stevenson, T., and Murphy, S. F. (1893). A treatise on hygiene and public health, Lond., 2, 433.

Stocks, P. (1941). J. Roy. Stat. Soc., 104, Pt. 4, 311. (1942). Ibid, 105, Pt. 4, 259.

(1943). Lancet, 1, 672.

(1944a). Ibid., 2, 65.

- (1944b). Min. of Health Monthly Bulletin, 3, 7. (1944c). Proc. rov. Soc. Med., 37, 593.

_ , and Karn, M. N. (1928). Ann. Eugen., Camb., 3, 361 .

- (1932). J. Hig., Camb., 32, 581.

Trevelyan, G. M. (1944). English social history, Lond.

Woods, H. M. (1933). Med. Res. Council, Special Report Series, No. 180.

Wright, G. P., and Wright, H. P. (1942). J. Hyg., Camb., 42, 451 . 